\title{
Interfaces rodoviário-urbanas no processo de produção das cidades: estudo de caso do contorno rodoviário de João Pessoa, PB, Brasil
}

\author{
Motorway-urban interfaces in the process of production \\ of cities: case study of the João Pessoa ring road, PB, \\ Brazil
}

\begin{abstract}
Alexandre Augusto Bezerra da Cunha Castro
Ricardo Almeida de Melo

José Augusto Ribeiro da Silveira

Geovany Jessé Alexandre Silva

Tomás Albuquerque Lapa

\section{Resumo}

A

s rodovias desempenham função importante no processo de estruturação das cidades, por facilitar os deslocamentos interurbanos. No entanto, quando absorvidas pela malha urbana de uma cidade, essas rodovias desenvolvem dinâmicas particulares com o espaço intraurbano no qual estão inseridas, com alterações na acessibilidade, na morfologia e no uso e ocupação da terra urbana. Com base nesse contexto, este artigo tem por objetivo analisar as dinâmicas entre a implantação do contorno rodoviário da BR-230 e o processo de produção do espaço intraurbano da cidade de João Pessoa-PB, entre os anos de 1963 e 2013, em termos de morfologia, uso e ocupação do solo urbano. O método empregado foi o da Lógica Evolutiva do Tecido Urbano, que divide a evolução urbana em três estágios: superação de limites, crescimento e combinação/conflitos. O método foi associado a ferramentas analíticas, como a Sintaxe Espacial e softwares de Sistema de Informação Geográfica. Os resultados mostram que a rodovia impulsionou o espraiamento da cidade para o setor sul e produziu uma malha urbana tentacular, onde também se identificou o padrão de crescimento horizontal e fragmentado, alterações na acessibilidade, uso do solo e na segregação socioespacial.

Alexandre Augusto Bezerra da Cunha Castro Universidade Federal da Paraíba João Pessoa - PB - Brasil

Ricardo Almeida de Melo Universidade Federal da Paraíba João Pessoa - PB - Brasil

José Augusto Ribeiro da Silveira

Universidade Federal da Paraíba João Pessoa - PB - Brasil

Geovany Jessé Alexandre Silva Universidade Federal da Paraíba João Pessoa - PB - Brasil

Tomás Albuquerque Lapa Universidade Federal de Pernambuco Recife - PE - Brasil

Recebido em 08/10/14 Aceito em 05/05/15

Palavras-chaves: Contorno rodoviário. Expansão urbana. Morfologia urbana. Uso do solo.

\section{Abstract}

Motorways play an important role in the development of the structure of cities, as they facilitate long distance journeys. However, when absorbed into the urban fabric, motorways develop particular dynamics with the intra-urban space where they are inserted, changing accessibility, morphology and the use and occupation of urban land. The aim of this paper is to analyse the dynamics between the implementation of the BR-230 motorway ring road and the process of urban space production in the city of João Pessoa-PB, Brazil, between 1963 and 2013, in terms of morphology and the use and occupation of urban land. The method employed was the Evolutionary Logic of the Urban Fabric, which divides urban evolution into three stages: overcoming limits, growth and combination/conflicts. This method was used in association with analytical tools, such as the Space Syntax software and the Geographic Information System. The results showed that the motorway boosted urban sprawl towards the southern sector of the city and produced a sprawling urban area. The study also identified a horizontal and fragmented growth pattern, changes in accessibility, land use and socio-spatial segregation.

Keywords: Ring road. Urban Sprawl. Urban morphology. Land use.
\end{abstract}




\section{Introdução}

As estradas tiveram contribuição importante no processo de estruturação das cidades, por poder influenciar no uso e ocupação do solo urbano, além de possibilitar deslocamentos humanos e trocas de informação e mercadorias. A partir dos fenômenos da Revolução Industrial, no século XIX, foram produzidos novos modais de transporte, tecnologias e infraestruturas viárias, como as ferrovias, as rodovias e o automóvel (GREEN; WEGENER, 1997).

No cenário brasileiro, a década de 1950 foi importante para a atração de investimentos e favoreceu o desenvolvimento de cidades de porte médio, que passaram por um crescimento populacional acelerado, tendo recebido uma série de equipamentos de abrangência regional, a exemplo de anéis e contornos rodoviários (VILLAÇA, 2001; SANTOS, 2005).

Nas duas décadas seguintes, sob o pretexto de uma política de integração nacional, o Estado promoveu a construção em massa de rodovias, anéis e contornos rodoviários. Esse incentivo ao padrão rodoviário de produção urbana gerou a ampliação da circulação de automóveis. Com base na ideologia de modernização do país, o privilégio da circulação de veículos automotores conduziu o modelo automobilístico-rodoviário para o interior do planejamento urbano, e a produção do espaço urbano passou a ser influenciada pelas supostas facilidades de deslocamento promovidas por aquele modelo (VASCONCELLOS, 2001).

Como consequência do modelo de planejamento citado, os contornos rodoviários próximos às cidades atraíram a construção de novos tecidos urbanos, tornando-se assim a base física de vetores de expansão urbana. Além disso, ao serem absorvidas por esses tecidos urbanos, as rodovias apresentam interfaces com o ambiente urbano que geram impactos positivos e negativos às cidades. Entre os aspectos positivos, pode-se citar sua importância para o sistema logístico nacional, através da melhoria do escoamento de mercadorias e dos deslocamentos interurbanos de passageiros. Entre os efeitos negativos registra-se o de cisão urbana.

Assim, o objetivo deste artigo é apresentar um estudo das interfaces existentes entre a dinâmica do contorno rodoviário da BR-230 e o processo de expansão urbana da cidade de João Pessoa, PB, entre os anos de 1963 e 2013, no que diz respeito ao uso e ocupação do solo urbano e a sua morfologia. O estudo busca contribuir para o entendimento da história recente da expansão urbana da cidade citada, bem como para a temática de rodovias urbanas, a partir da aplicação de ferramentas analíticas e geoespaciais.

\section{Anel e contorno rodoviários}

Conceitualmente, um anel rodoviário é uma via destinada à circulação de veículos nas bordas urbanas, com o objetivo de evitar ou minimizar o tráfego veicular no espaço intraurbano. Sua forma é caracterizada por circundar todo o perímetro urbano de uma cidade. Um contorno rodoviário possui as mesmas funções do anel rodoviário, porém a principal diferença é que este não circunda completamente o perímetro urbano; ele apenas interliga uma parte da cidade e pode ser chamado também de rodovia perimetral (BRASIL, 2002).

A partir dessas localizações e configurações físicas, nota-se que a estrutura de uma rodovia não abrange o deslocamento seguro de pedestres ou outros modos de locomoção num espaço exclusivo, mesmo que a rodovia atravesse uma área urbana. Essa dinâmica de apropriação mostra conflitos de usos do solo e fluxos urbanos e a configuração da rodovia como um local que apresenta segurança reduzida para usuários de modos de transporte não motorizados, por não possuir, em sua secção típica, infraestruturas necessárias para ofertar tais deslocamentos de maneira adequada, a exemplo de calçadas (JIANG; PENG, 2012).

\section{Dinâmica de produção do espaço intraurbano}

O espaço intraurbano é definido por Villaça (2001) como sendo o espaço interno de uma cidade. Diferentemente dos espaços regionais, estruturados pelos fluxos de informações, capital e mercadorias, o espaço intraurbano é estruturado por fluxos e deslocamentos humanos, sejam eles a serviço da força de trabalho ou a serviço da força de consumo, que possuem relação direta com a prática capitalista devido à influência de territórios comerciais ou de serviços na estruturação espacial da cidade.

Nesse contexto, os transportes podem relacionar-se com a produção de localizações e no processo de ocupação da terra urbana. A qualidade da acessibilidade altera o valor de uso da terra e cria localizações morfologicamente diferentes e ocupadas por classes sociais ou usos distintos. Quanto melhor a acessibilidade, maior será a facilidade de acesso ao solo urbano de determinada 
localização e, por conseguinte, o valor da terra será maior e seu uso será especializado.

Com relação à dinâmica entre a produção do espaço e o planejamento dos transportes, Oliveira (2006) afirma que o sistema de transportes possui relação direta com a morfologia e evolução do espaço intraurbano devido à criação e desenvolvimento das infraestruturas inerentes aos espaços livres públicos viários e ao uso e ocupação do solo urbano. Segundo Souza (2007), quando o modelo rodoviarista é empregado, a cidade é estruturada de forma que há maior gasto com infraestruturas urbanas, além da tendência da formação de vazios urbanos associados à especulação imobiliária, principalmente em países emergentes, quando esse modelo de cidade é hipoteticamente chamado de "rodópolis".

\section{Teoria da Sintaxe Espacial}

A acessibilidade e o desempenho morfológico das cidades podem ser quantificados a partir da Sintaxe Espacial. Criada a partir da Teoria da Lógica Social do Espaço (HILLIER; HANSON, 1984), a Sintaxe Espacial, de acordo com Saboya (2007), descreve a configuração morfológica dos espaços livres passíveis de circulação (vias, ruas, praças, entre outros), a partir de medidas quantitativas, as quais permitem entender aspectos importantes do sistema urbano, a exemplo da acessibilidade e da distribuição de usos do solo. Dessa forma, a Sintaxe Espacial expressa o nível de integração de um espaço livre a partir das conexões e linearidade, comprimento desses espaços livres e arranjo do sistema de espaços livres no ambiente urbano.

O potencial de acessibilidade medido tem como principal variável a distância topológica, ou seja, as mudanças de direção que um indivíduo executa durante um percurso, e considera que todos os eixos diretamente conectados a determinada linha estão a um passo topológico desta (ou realizam apenas uma mudança de direção para alcançá-la). As linhas subsequentes a esses eixos estão a dois passos topológicos do primeiro eixo e assim sucessivamente. Entre as principais medidas de acessibilidade utilizadas na Sintaxe Espacial está a integração. Descrita por Hillier (2009) como sendo a facilidade para chegar a uma via a partir de todas as outras, a integração pode ser analisada em duas escalas:

(a) integração global $(\mathrm{R} n)$ : calcula a distância topológica de determinada linha em relação a todas as linhas do sistema ${ }^{1}$. Dessa forma, caso o sistema

${ }^{1}$ Entende-se o sistema enquanto o grupo total de linhas axiais a serem estudadas. 0 sistema não tem um tamanho específico e seja o espaço intraurbano de uma cidade, é possível pressupor que, quanto mais compacta a cidade, menores serão os passos topológicos e a profundidade será mais rasa e integrada, e viceversa; e

(b) integração local (R3): de acordo com Saboya (2007), a integração local, também chamada de integração de raio limitado, é calculada de forma que o valor de integração seja obtido apenas para as linhas localizadas dentro de determinado limite de passos topológicos. Costumam-se utilizar três passos topológicos para a integração local, sendo conhecida, assim, como integração R3.

Os cálculos são feitos a partir de softwares específicos, que calculam os valores de integração da malha viária, a exemplo do Space Syntax Analysis, Depthmap, Syntax2D, Mindwalk.

\section{Impactos das rodovias em meio urbano}

A inserção de contornos rodoviários em áreas urbanas pode ocasionar uma série de impactos, como processos de suburbanização e migração de parte da população de bairros centrais para a periferia. De acordo com Baum-Snow (2007), nas cidades em que se construiu um contorno rodoviário os bairros de áreas centrais sofreram redução de $17 \%$ da população, enquanto nas cidades sem contornos rodoviários a população nesses mesmos bairros cresceu $8 \%$.

Também podem ocorrer processos de segregação socioespacial, com a concentração da população de baixa renda às margens das rodovias, processos de favelização, alteração na morfologia, podendo produzir espaços mais segregados e alterações no uso e ocupação da terra urbana (BRASIL, 2005; PINTO, 2012; TAVARES, 2013; BALAKRISHNAN, 2013). A segregação fica mais visível ao analisar o processo de produção do espaço. Van Nes (2001) observou que a implantação de contornos rodoviários pode ocasionar transformações nos padrões de distribuição das áreas comerciais e industriais da cidade, uma vez que as alterações morfológicas resultantes da construção da via modificam o potencial de acessibilidade da rodovia com a cidade, criando assim novos vetores comerciais.

Outro impacto ocasionado por vias expressas é o efeito barreira ${ }^{2}$, caracterizado pela perda de interações sociais (MOUETTE, 1998;

pode ser desde a área de influência de uma rua, um bairro, o espaço intraurbano de uma cidade, até uma rede metropolitana. 2 De acordo com Clark e Hutton (1991), o termo originou-se na primeira metade do século XX e relacionava o desenvolvimento dos bairros-dormitórios em periferias urbanas e a consequente deterioração da vida social da população afetada. 
APPLEYARD, 1981), que pode atingir três escalas:

(a) impactos primários, nos quais ocorrem consequências diretas do sistema de transportes e referem-se a alterações imediatas na acessibilidade e mobilidade da via em seu entorno imediato;

(b) impactos secundários, quando ocorrem alterações nos padrões de viagens e no comportamento dos indivíduos afetados; e impacto na área de influência direta, entendendo este como sendo a área contida numa faixa de $500 \mathrm{~m}$ ao longo da via; e

(c) impactos terciários, com alterações globais na estrutura intraurbana.

Essas escalas de impacto são similares às descritas por Dron e Lara (1995), que classificam como impactos primários a redução dos deslocamentos curtos, devido às dificuldades na travessia; impactos secundários, a mudança na apreensão do espaço local, devido à redução da interação social e à redução dos deslocamentos e interações sociais; e terciários, que são as modificações do funcionamento do local por mudanças no uso do solo.

De acordo com Vasconcellos (2008), as rodovias localizadas em áreas urbanas são um exemplo do efeito barreira, uma vez que elas causam o rompimento do tecido social existente e cria um novo ambiente baseado na circulação de automóveis. A ocorrência desse fenômeno pode ocasionar alterações na acessibilidade dos pedestres e, no caso das rodovias, potencializa o risco de atropelamentos, uma vez que a estrutura física da rodovia não foi planejada para receber o deslocamento de modos não motorizados, a exemplo de ciclistas e pedestres (SILVA JÚNIOR; FERREIRA, 2008).

Além disso, a temática tem ganhado mais notoriedade a partir do aumento da importância da mobilidade urbana na qualidade de vida da população. Estudos mais recentes, a exemplo dos estudos desenvolvidos por Piatkowsky (2011) e pelo ITDP e EMBARQ (INSTITUTE...; EMBRAQ, 2013), mostram uma tendência de intervenções em rodovias urbanas, como municipalização da via, modificações que teriam trazido benefícios. Porém, faz-se necessário estudar previamente o fenômeno de implantação das rodovias urbanas para que se possa entender como os impactos surgiram.
A maioria dos estudos já realizados que abordam a BR-230 em João Pessoa (LAVIERI; LAVIERI, 1992; COUTINHO, 2004; SILVEIRA, 2004; OLIVEIRA, 2006; NEGRÃO, 2012) não analisa a influência dessa rodovia no processo de expansão da cidade, como também em sua conformação morfológica.

Outros estudos pesquisados mostram certa convergência acerca dos impactos causados por rodovias que foram absorvidas pelos tecidos urbanos. As interfaces entre a via e a cidade ocasionam alterações na acessibilidade, mobilidade, padrões de uso e ocupação do solo urbano, e alterações na setorização de classes sociais ao longo dos eixos rodoviários. Esses impactos, no entanto, ocorreram em momentos, escalas e intensidades diferentes, variando conforme a dinâmica de cada cidade estudada.

\section{Objeto de estudo}

O objeto de estudo deste trabalho é delimitado pelo contorno rodoviário da BR-230 e por sua área de influência direta, numa faixa de $500 \mathrm{~m}$ ao longo da via, localizados em linha central do espaço intraurbano na cidade de João Pessoa, Estado da Paraíba ${ }^{3}$.

De acordo com a caracterização utilizada pela Empresa Brasileira de Planejamento de Transportes (BRASIL, 1980), o contorno rodoviário da BR-230 é do gênero rodovia, espécie intraurbana e de categoria arterial (por seu papel de escoar grandes fluxos de veículos e velocidade média maior que uma via urbana convencional). No espaço da cidade, adquiriu características e dinâmicas intraurbanas típicas, o que resulta, daí, as interfaces aqui tratadas. Possui pista dupla com pavimentação asfáltica e predominantemente é uma via expressa.

O trecho da rodovia possui $10,6 \mathrm{~km}$ de extensão, locado entre o $\mathrm{Km}$ 17,5, no Hospital de Emergência e Trauma, e o Km 28,1, no Viaduto Ivan Bichara, no qual a BR-230 também se conecta com a Avenida Cruz das Armas e a BR101 (Figura 1). 
Figura 1 - Localização do objeto de estudo

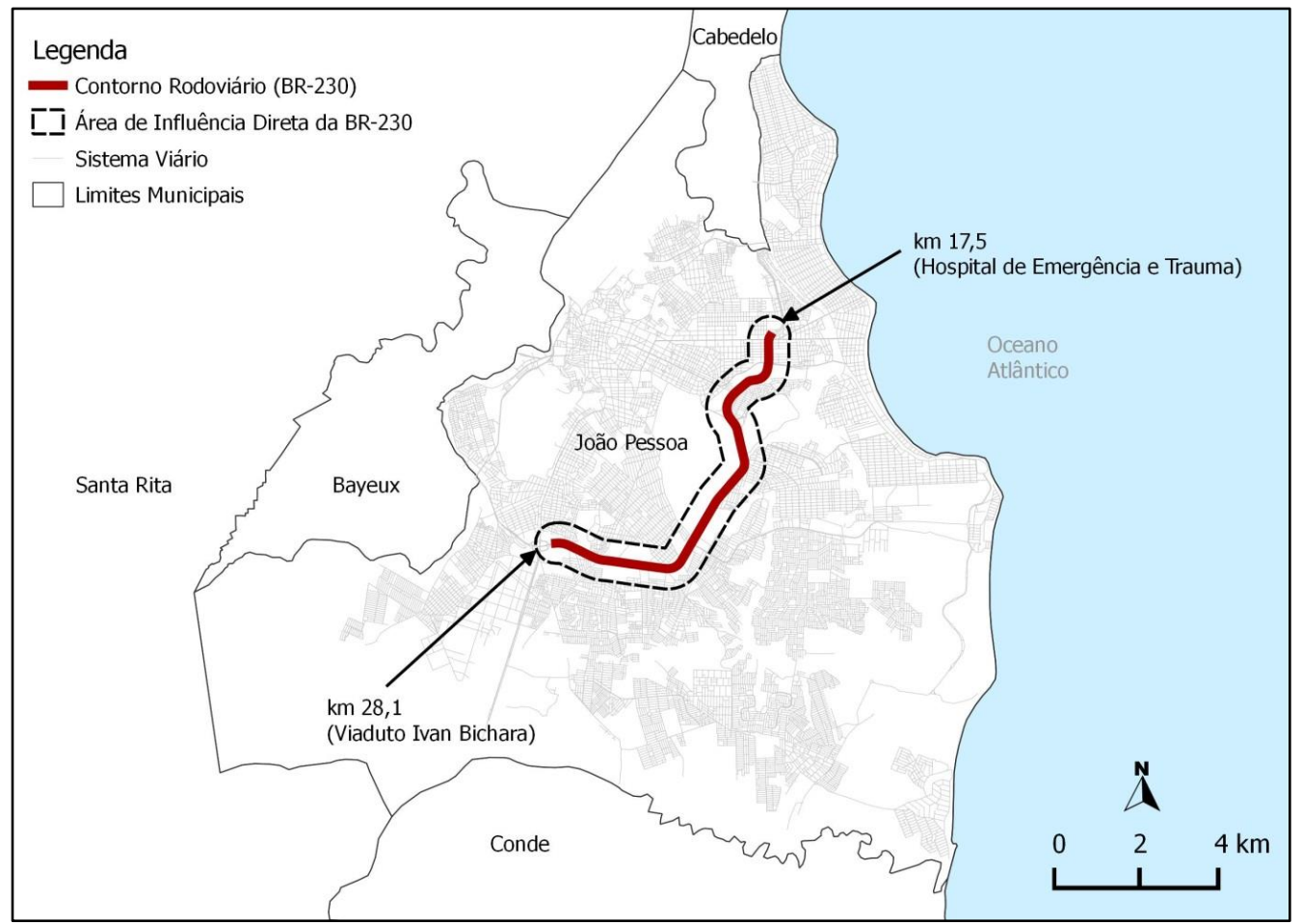

\section{Método}

O método utilizado consiste na lógica evolutiva do tecido urbano, desenvolvido por Panerai et al. (1986, 2004, 2013), que, de acordo com Silveira (2004), analisa a expansão urbana em três estágios evolutivos não lineares:

(a) superação de limites: estágio em que o crescimento urbano, em termos relativos, tem como ponto de partida a superação de um limite. Esse limite é entendido como barreira ao crescimento do tecido urbano, podendo ser constituído por um obstáculo geográfico (relevo, curso d'água, lago, floresta, etc.) ou construído (muralha, fosso, canal, estradas, ferrovia, propriedades privadas);

(b) crescimento: estágio em que ocorre o processo de expansão da malha urbana após a superação de limites, caracterizado, em termos relativos, pelo processo de formação de novos assentamentos urbanos, como bairros, construção de conjuntos habitacionais, entre outros. Considera-se, no aumento da extensão territorial da urbe, não apenas a área edificada, como também o processo de ocupação de um espaço apenas loteado; e

(c) combinação e conflitos: estágio em que são expostas as problemáticas decorrentes do processo de expansão urbana descritos no estágio de crescimento. Esses conflitos podem ter origem física e/ou social.

A aplicação desse método foi realizada após investigação aprofundada do objeto de estudo, sendo constatadas fases evolutivas aproximadas aos estágios - movimentos de transformação urbana apresentados por Panerai et al. (1986). Da mesma maneira, os estudos de Panerai também propiciaram aqui o aprofundamento na investigação da dinâmica ao longo do contorno em tela e das interfaces estabelecidas com seu entorno.

Além do que já foi exposto, o método facilita o entendimento do processo de expansão urbana, com a visualização de três estágios espaçotemporais, a partir de suas características predominantes (DEL RIO, 1990; NEGRÃO, 2012). A definição do recorte temporal de cada estágio foi estabelecida de acordo com a investigação cartográfica realizada, de forma a compatibilizar a análise subsequente, não linear entres esses estágios (Quadro 1).

Os mapas temáticos foram produzidos em base georreferenciada, com o software SIG (Sistema de Informação Geográfica) livre QGIS 2.4.0. A reconstrução da evolução urbana de João Pessoa foi realizada por meio de investigação cartográfica, usando mapas históricos da cidade (Quadro 2). 
Quadro 1 - Delimitação dos estágios evolutivos

\begin{tabular}{|cc|}
\hline Estágio & Período \\
\hline Estágio de Superação de Limites & $1963-1970$ \\
Estágio de Crescimento Urbano & $1970-2004$ \\
Estágio de Combinações e Conflitos & $2004-2013$ \\
\hline
\end{tabular}

Quadro 2 - Lista de mapas históricos

\begin{tabular}{|cc|}
\hline Ano & Fonte \\
\hline Até 1963 & Lavieri (1992) \\
1963 & Lavieri (1992) \\
1970 & Sudene (1970) \\
1979 & Lavieri (1979) \\
1985 & PDTU (1985) \\
1994 & PMJP (1994) \\
2004 & Oliveira (2006) \\
2013 & Base do Open Street Map \\
\hline
\end{tabular}

As geotecnologias podem ser importantes instrumentos para análises espaciais multitemporais em espaços urbanos ${ }^{4}$. Silva et al. (2007), Savioli (2008), Breunig e Mello (2010), Polidoro et al. (2010), Polidoro (2011), Donato (2010), Polidoro e Barros (2012) e Falcão, Castro e Silveira (2013) estudaram o crescimento urbano ao longo das rodovias a partir de análises espaciais multitemporais e com o uso de softwares SIG, com a identificação de padrões espaciais de crescimento ao longo do eixo rodoviário.

O emprego dessa ferramenta mostrou-se útil, uma vez que gera resultados mais precisos, que agregam um banco de dados geográficos, cujas informações podem ser cruzadas com outros dados. Sudhira, Ramachandra e Jagadish (2004), Jiang et al. (2007), Rafael et al. (2009) ${ }^{5}$ e Lima e Rêgo (2011) também empregaram imagens de satélite para a quantificação da distensão urbana e de outros índices, que demandaram um conjunto de informações e dados que podem apresentar dificuldade na obtenção, como imagens de média resolução.

A análise também teve suporte metodológico a partir do uso da Sintaxe Espacial (Teoria da Lógica Social do Espaço), criada por Hillier e Hanson (1984). O método, que consiste na identificação de linhas de acessibilidade a partir do sistema de

${ }^{4}$ De acordo com Ribeiro e Holanda (2003, p.1), "Remote sensing and the geoprocessing techniques constitute powerful tools to monitor the evolution of urban growth, to manipulate various sorts of data and to simulate models that help in developing urban plans".

${ }^{5} \mathrm{O}$ uso de imagens de média resolução do satélite Landsat pode ocasionar conflitos na interpretação automatizada dos pixels. Dessa forma, os autores também empregaram a fotointerpretação para avaliar os locais que são "área construída" ou "solo exposto". espaços livres, foi adaptado para considerar o traçado do leito carroçável, conforme modelo adotado por Medeiros (2006). Esse mapa axial foi processado no software livre DepthmapX 0.30 (VAROUDIS, 2014), pelo qual se obtiveram os valores de integração. Os dados foram integrados com outros dados geográficos no software QGIS.

Assim, a utilização da sintaxe espacial, em processos de expansão intraurbana pode contribuir no entendimento do desenvolvimento morfológico viário desse espaço, bem como analisar a influência de determinadas vias ou setores na configuração morfológica da cidade durante o processo evolutivo (NOGUEIRA, 2006; CAVANCANTE; JALES, 2008; MEDEIROS; BARROS; OLIVEIRA, 2011). Os resultados que podem ser obtidos ajudam a compreender como a facilidade de deslocamento (macroacessibilidade), vista com base em dados sintáticos, contribui na criação de vetores de crescimento. Tavares (2013) aplicou a teoria da Sintaxe Espacial em uma via expressa de Coimbra, Portugal, e analisou como seu desempenho morfológico atraiu a implantação de novos investimentos no local.

\section{Estágios evolutivos da dinâmica intraurbana de João Pessoa (1963-2013)}

\section{Estágio de superação de limites}

O cenário estabelecido e os elementos e processos de transformação urbana não exclusivamente lineares no final da década de 1950 e no início da década de 1960 serviram de alicerces para a estruturação rodoviária do estado. Em posição estratégica e de interesses regional e nacional, a 
cidade de João Pessoa se situa no percurso das principais rodovias da Paraíba, por servir de ligação entre o Porto de Cabedelo e o interior do estado, cujos deslocamentos regionais passam por seu espaço intraurbano. Sua estrutura espacial estava delimitada historicamente a partir de dois vetores de crescimento, localizados nos corredores Cruz das Armas, na direção sul, e Epitácio Pessoa, na direção leste, este último que também delimitava o núcleo integrador da cidade (Figura 2).

Havia então a necessidade da criação de uma rota alternativa que deslocasse o fluxo interurbano para fora da cidade, o que facilitaria o deslocamento para o interior. Surgiu daí a necessidade de um contorno rodoviário na cidade de João Pessoa. Associado com a decisão de implantar o campus da Universidade da Paraíba, em 1958, o Jornal A União de 20 de março noticiou a iminente construção de um contorno rodoviário em João Pessoa, semelhante à proposição presente no Plano de Remodelação e Extensão Urbana, de 1933 (PEREIRA, 2008). Esse fato marca o interesse do Estado na criação de novas rotas rodoviárias sob um planejamento de integração nacional.

Nesse cenário, os primeiros planejamentos estruturados que apontavam a necessidade de construção de um contorno rodoviário surgiram a partir da perspectiva desenvolvimentista do Governo Federal, por meio do "Plano Rodoviário Nacional de 1956-1960" (TRAJANO FILHO, 2003). A concretização do projeto veio em 1962, quatro anos após a veiculação das primeiras intenções de construção da rodovia. O Diário Oficial da União $\mathrm{n}^{\mathbf{0}} 240$, de 20 de dezembro, aprovara orçamento para obras da BR-53, “inclusive ponte sôbre o Rio Sanhauá e contôrno da cidade de João Pessoa" (BRASIL, 1962, p. 778).

A obra para a BR-53 foi dividida em dois segmentos: o primeiro segmento foi uma ponte sobre o Rio Sanhauá, além da construção de uma rodovia que aproveitaria uma antiga estrada no município de Bayeux. Esse trecho de rodovia entroncava com a BR-23 em Santa Rita, e faria ligação com Natal-RN. O segundo segmento foi um contorno rodoviário, que visava o acesso a outros trechos de rodovia sem a necessidade de penetrar a área urbana de João Pessoa. Com o objetivo de conectar-se ao trecho Cabedelo-João Pessoa da BR-53, o contorno começa próximo à Avenida Epitácio Pessoa, atravessa o Rio Jaguaribe, tangencia a Universidade Federal da Paraíba e segue pela região sul, em zona rural. Atravessa novamente o Rio Jaguaribe, conectandose à junção da BR-11, BR-23 e Avenida Cruz das Armas. O acesso para o interior da Paraíba, bem como para os Estados de Pernambuco e Rio Grande do Norte, foi facilitado. O contorno rodoviário de João Pessoa criou um ponto nodal importante para esses deslocamentos, inclusive facilitando o acesso para o espaço intraurbano da capital paraibana (Figura 3).

Essa conformação viária reforça a importância que a BR-53 tinha para João Pessoa naquele momento, na escala regional. A adição de uma nova linha de acessibilidade promoveria o deslocamento regional com o mínimo de interferência no ambiente urbano. Além disso, a rota facilitaria o acesso de pessoas de outras cidades e estados para a Universidade Federal da Paraíba. Salienta-se que essas obras rodoviárias não visavam, num primeiro momento, à implantação de infraestruturas com o objetivo de atrair investimentos e adensamento populacional. No entanto, a conformação da rodovia, ao conectar um equipamento de grande porte, como a UFPB, com a malha urbana existente, viabilizou o processo de expansão urbana em direção ao sul, uma vez que em 1964 o Estado começou a investir na política habitacional, a partir da criação do Banco Nacional de Habitação. As terras lindeiras à BR-230 (nome dado à BR-53 após o Plano Nacional de Viação de 1964) eram espaços propícios à instalação desse tipo de equipamento.

Após a construção do contorno rodoviário, os valores de integração da cidade se reduziram, uma vez que a rodovia apresentava pouca conectividade com o tecido urbano de João Pessoa, servindo apenas para deslocamentos interurbanos. O contorno ainda não exercia funções locais e era a linha-espaço mais avançada na porção sudeste da cidade (Figura 4 e Tabela 1). 
Figura 2 - Integração global de João Pessoa antes da construção da BR-230

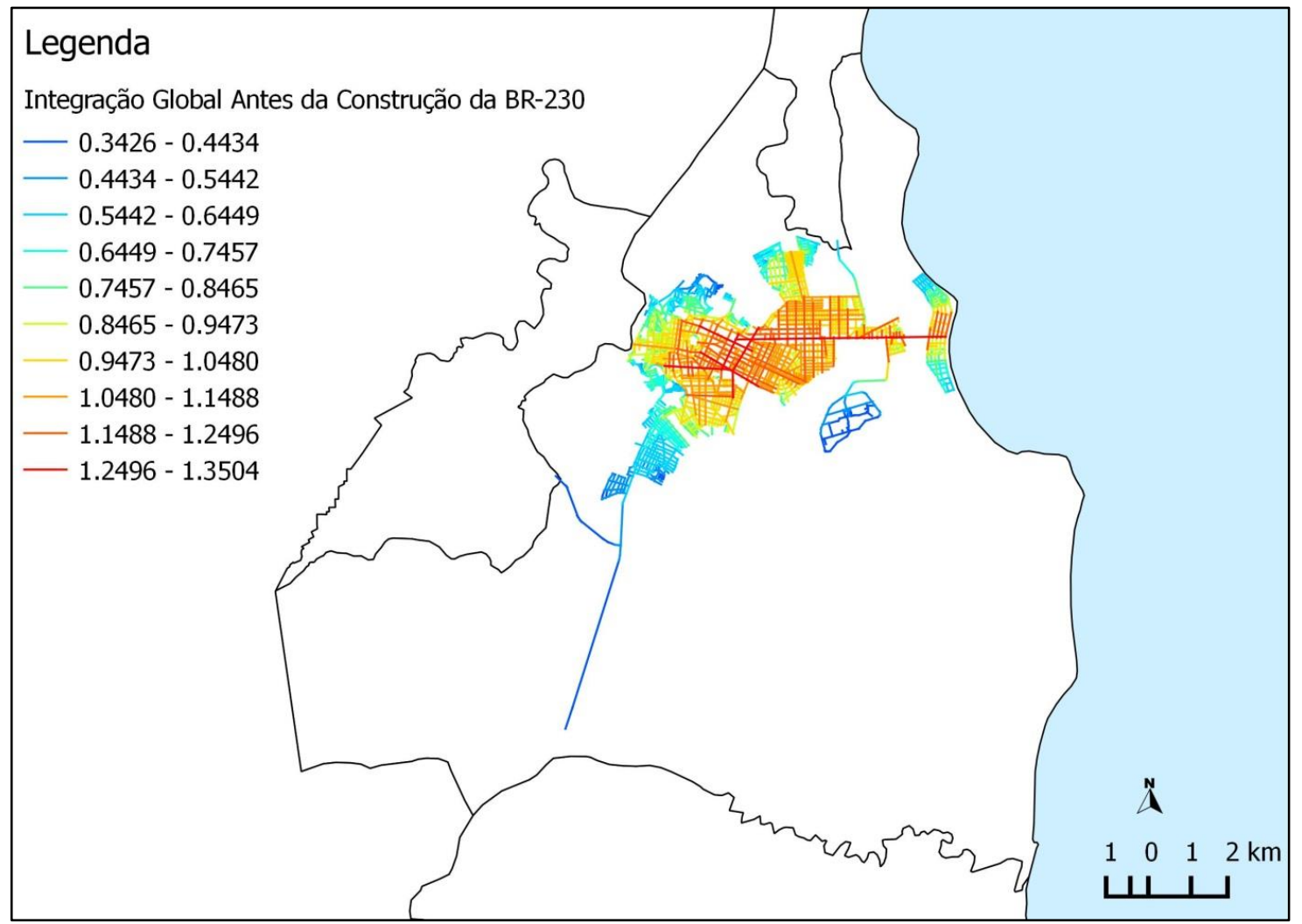

Figura 3 - Mapa de localização do objeto de estudo

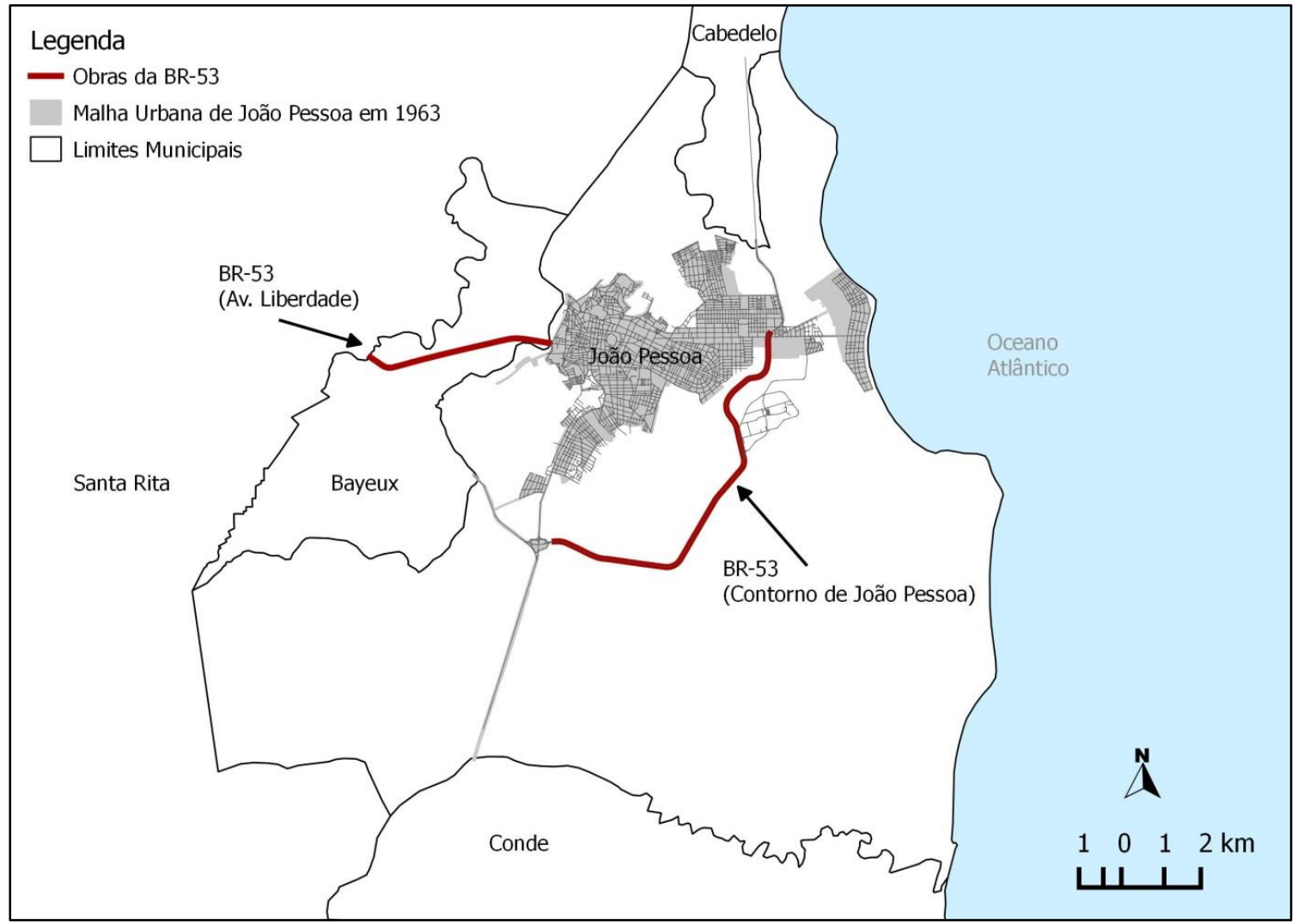

182 Castro, A. A. B. de C.; Melo, R. A. de; Silveira, J. A. R. da; Silva, G. J. A.; Lapa, T. A. 
Figura 4 - Integração global de João Pessoa em 1963, depois da construção da rodovia

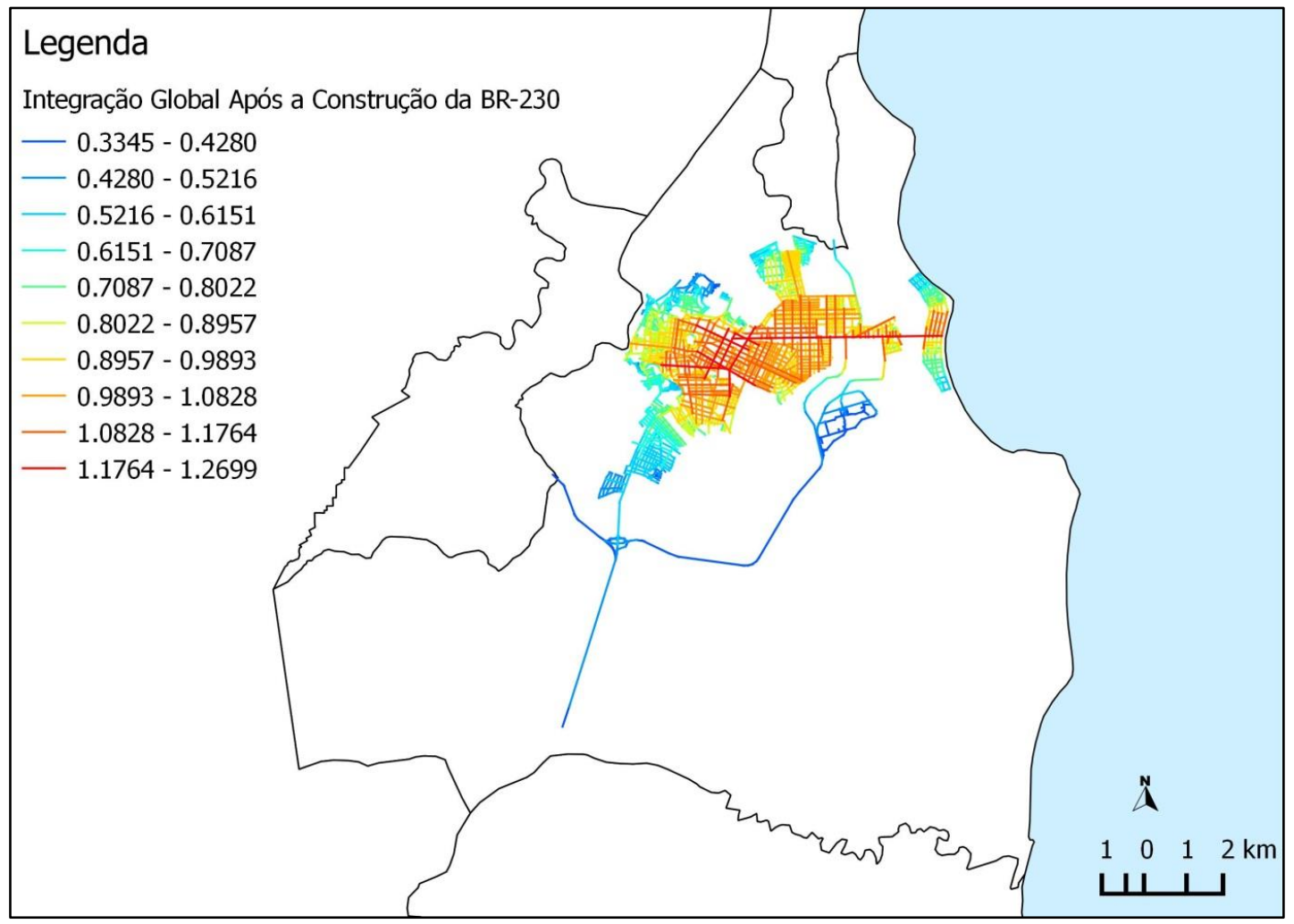

Tabela 1 - Integração global em 1963, antes e depois da construção da rodovia

\begin{tabular}{ccc}
\hline Ano & João Pessoa & Contorno Rodoviário \\
\hline 1963 (antes da construção da rodovia) & 0,8114 & 0 \\
1963 (depois da construção da rodovia) & 0,7662 & 0,5604 \\
\hline
\end{tabular}

O potencial de dispersão da malha urbana da cidade viria a se concretizar nos anos seguintes. A produção de conjuntos habitacionais em João Pessoa começaria apenas em 1968, com os conjuntos Jardim 13 de Maio, Redenção, Boa Vista, Pedro Gondim e Cidade dos Funcionários, este que foi a primeira forma de ocupação lindeira à rodovia, os quais totalizavam 1.703 unidades habitacionais. No entanto, na ocupação do setor sudeste da cidade, em 1969 e 1970, houve a construção dos conjuntos Castelo Branco I e II, as primeiras ocupações urbanas a superar os limites da BR-230 e do vale do Rio Jaguaribe, o que representa não somente a tendência de urbanização na direção sudeste como também a demanda de uso do solo heterogêneo, que combina atividades comerciais e institucionais com residenciais, o que não tinha sido planejado após a construção da rodovia. Ao todo, foram entregues 2.894 unidades habitacionais nos dois primeiros anos de atuação do BNH (LAVIERI; LAVIERI, 1992).
Em 1970, a área urbana do município de João Pessoa ocupava $31,32 \mathrm{~km}^{2}$, com aumento de 10,94 $\mathrm{km}^{2}$ em relação a 1963, o que corresponde a $53,68 \%$. Os vazios existentes entre a BR-230 e a malha urbana de João Pessoa estavam sendo ocupados progressivamente. Apesar de as edificações ainda estarem localizadas no limite urbano, já ocorriam loteamentos e arruamentos além dos limites do Contorno Rodoviário, o que mostra a clara intenção de ocupação do setor sul da cidade. No total, $56,72 \%$ da área urbanizada na cidade ocorreu ao longo da rodovia, o que demonstra seu potencial enquanto magneto de assentamentos urbanos.

É perceptível a formação de dois vetores de crescimento distintos:

(a) o primeiro vetor é constituído a partir do movimento de atração da malha urbana tradicional até a rodovia, com a construção do conjunto Cristo Redentor, promovendo a ocupação de vazios 
urbanos e contribuindo com o adensamento da malha urbana;

(b) o segundo vetor se caracteriza pela expansão da malha urbana além dos limites da rodovia e do vale do Rio Jaguaribe, a sudeste, com a construção do conjunto Bancários (Figura 5).

Nos primeiros sete anos após a implantação do contorno rodoviário, a malha urbana de João Pessoa começou a sofrer os reflexos do processo de espraiamento. Os espaços-bairros mais avançados da cidade (Bessa, na faixa litorânea, e Bancários, no setor sudeste), por apresentarem pouca conectividade, estão morfologicamente menos integrados ao tecido da cidade, enquanto o Contorno Rodoviário, que passou a atrair loteamentos e edificações em sua região lindeira, já apresentava valores de integração maiores (Tabela 2).

Espacialmente, o eixo composto pelo centro tradicional e o setor estruturado pela Avenida Epitácio Pessoa são os espaços mais integrados da cidade. Paradoxalmente, apesar do aumento dos valores de integração, o contorno rodoviário e os novos bairros contíguos estão entre os principais setores segregados de João Pessoa, em função da localização periférica e da pouca conectividade com o núcleo integrado e a suas oportunidades urbanas. A implantação do conjunto Cristo Redentor nas proximidades da BR-230 contribuiu para o aumento da integração da rodovia e consequentemente para seu potencial uso intraurbano (Figura 6).

Os dados apresentados a partir dos fenômenos ligados ao Contorno Rodoviário nesse primeiro período mostram que, ao considerar que sua implantação se deu a partir de 1963 e a ocupação do terreno destinado à UFPB ocorreu a partir de 1965, e ainda com base no pressuposto de Panerai et al. $(1986,2004,2013)$ de que o estágio de superação de limites se dá pelo avanço do tecido urbano sobre um limite geográfico, pode-se considerar que o contorno rodoviário de João Pessoa representou um marco referencial na superação do Rio Jaguaribe e na ocupação urbana da cidade em direção sudeste.

Figura 5 - Crescimento urbano de João Pessoa entre 1963 e 1970 e seus dois vetores

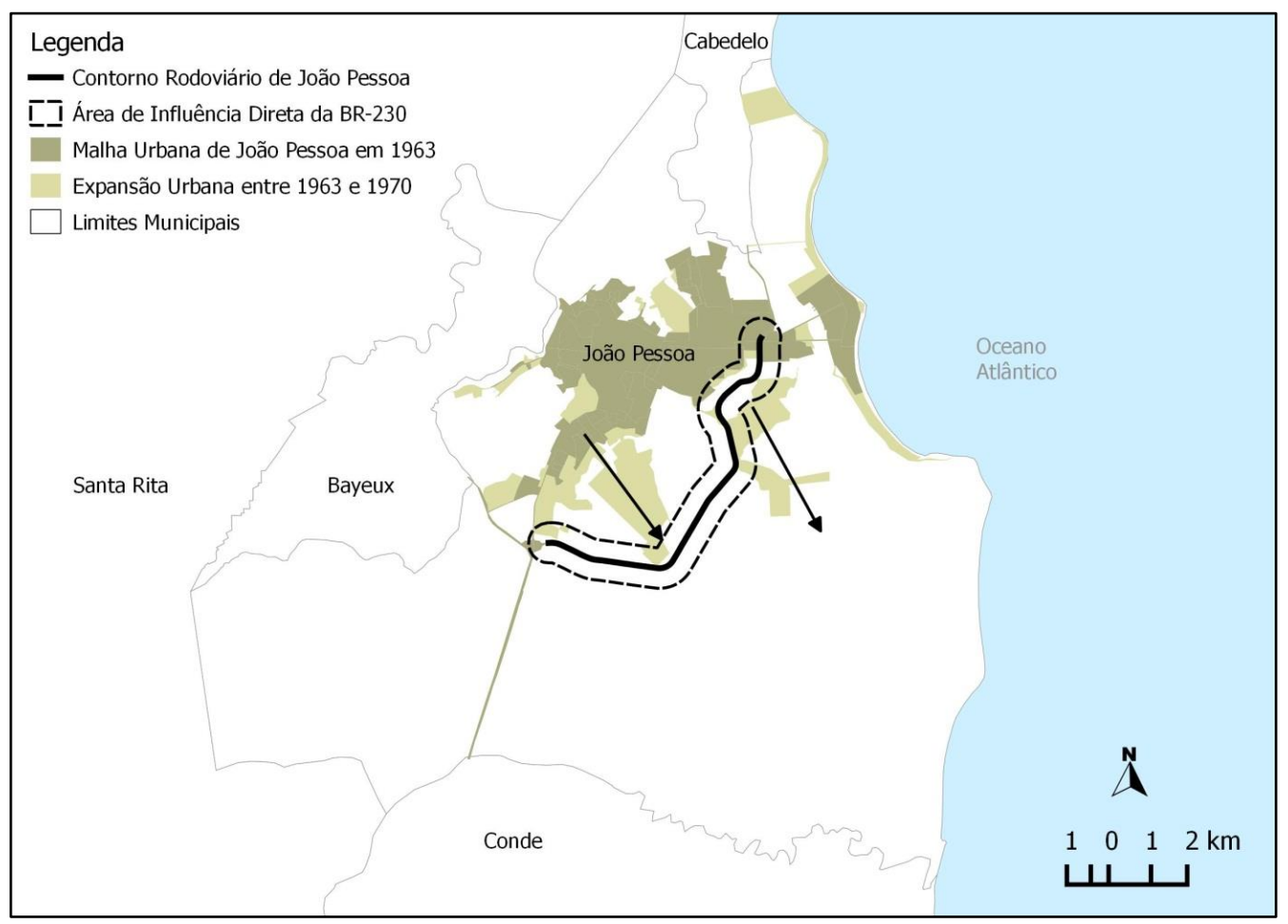

Tabela 2 - Integração global (1963 a 1970)

\begin{tabular}{lcc}
\hline \multicolumn{1}{c}{ Espaço } & $\mathbf{1 9 6 3}$ & $\mathbf{1 9 7 0}$ \\
\hline João Pessoa & 0,7662 & 0,6308 \\
Contorno Rodoviário & 0,5604 & 0,5808 \\
Epitácio Pessoa & 1,2610 & 1,0308 \\
\hline
\end{tabular}

184 Castro, A. A. B. de C.; Melo, R. A. de; Silveira, J. A. R. da; Silva, G. J. A.; Lapa, T. A. 
Figura 6 - Integração global de João Pessoa e Contorno Rodoviário em 1970

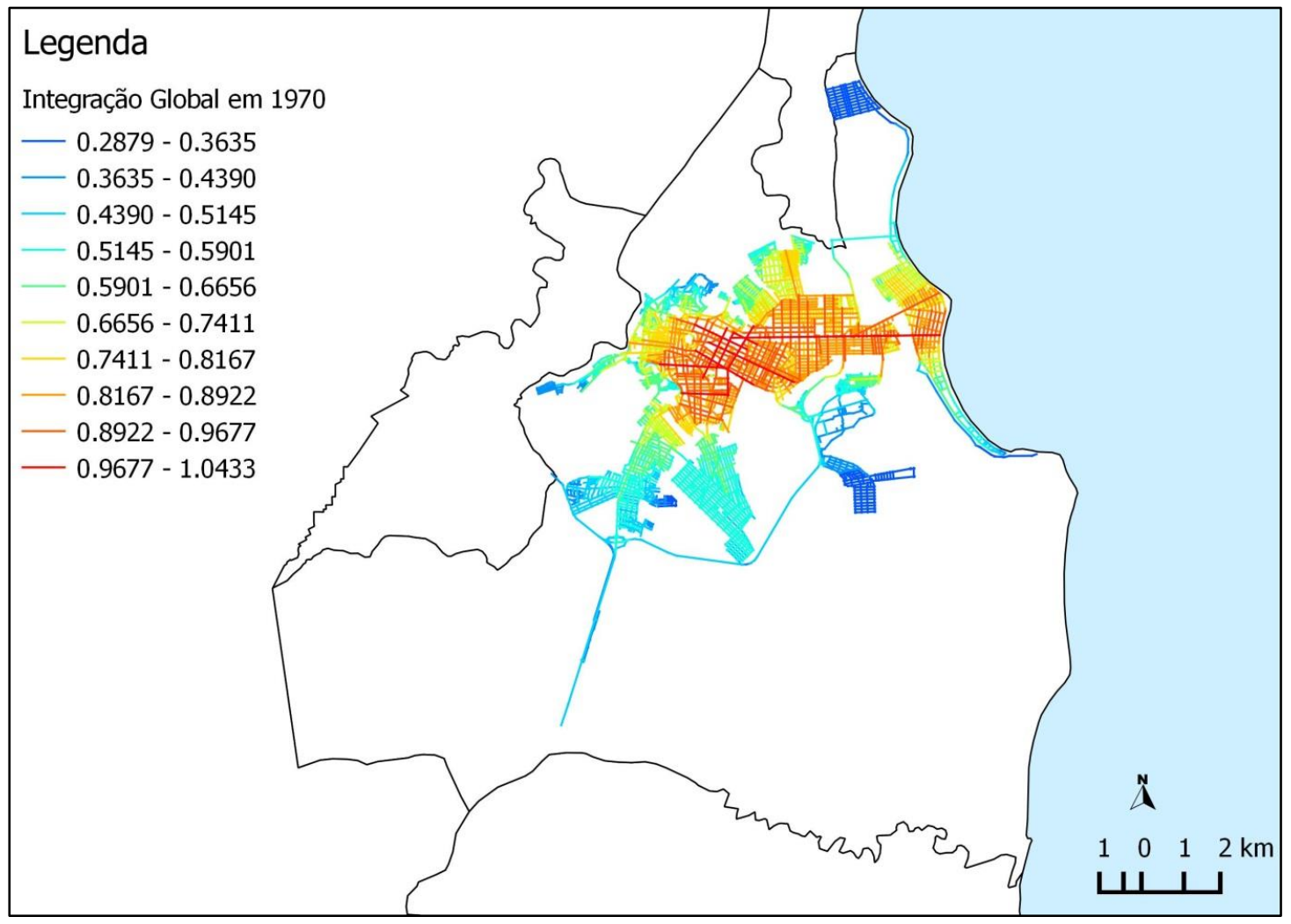

\section{Estágio de crescimento}

Os anos 1970 representaram um avanço importante no crescimento de João Pessoa. Após a implantação de infraestruturas de porte regional, a exemplo do Contorno Rodoviário da BR-230, e a atuação do BNH, criaram-se as condições de promover o crescimento da malha urbana da cidade. Entre 1970 e 1979, a área de influência da rodovia passou por um processo de apropriação mais acelerado que a média da cidade. Foram construídos treze conjuntos habitacionais em João Pessoa, com 5.979 unidades ao todo, ante 2.894 unidades na década de 1960 , o que representa um aumento de $106,59 \%$ no número de unidade habitacionais entregues pelo BNH. Além disso, desse total de conjuntos nove foram construídos na área de influência do Contorno Rodoviário, o equivalente a $69,23 \%$ dos projetos.

Esse período (1970-1979) marcou uma inversão nos valores de integração global de João Pessoa e do Contorno Rodoviário: com o processo de espraiamento, a cidade obteve um valor menor de integração global $(0,513)$ em relação a 1970. Enquanto os espaços lindeiros da BR-230 foram ocupados e a malha urbana se distendia mais ao sul, a rodovia ia se tornando objeto-chave na interligação da "cidade antiga" (até 1963) e dos novos espaços ocupados, o que aumentou sua integração global para 0,5653. Apesar do valor menor que em 1970, tornou-se maior que a média da cidade (Figura 7).

Por sua vez, o período entre 1979 e 1985 foi marcado por mudanças mais significativas no uso do solo e morfologia urbana. $\mathrm{O}$ rápido crescimento da cidade, que aumentou em $222 \%$ o número de domicílios em vinte anos, recebeu também mais investimentos do poder público em infraestruturas, com a implantação do Projeto Cura nos bairros da orla marítima e no Cristo (LAVIERI; LAVIERI, 1992).

Até esse ponto, o percurso do contorno rodoviário de João Pessoa havia se tornado um local estratégico para o planejamento habitacional da cidade. De acordo com Lavieri e Lavieri (1992), os espaços adjacentes à BR-230, principal elemento viário estruturador do setor sul-sudeste da cidade, foi o local que recebeu a maioria das intervenções públicas em habitações de interesse social: ali foram construídas 6.965 unidades habitacionais, correspondendo a $82 \%$ do total de unidades implantadas no período. É importante salientar a dimensão territorial e populacional dos conjuntos, que, no espaço de três anos, representou 18,93\% mais unidades habitacionais que os nove anos anteriores: de 7.140 unidades entre 1970 e 1979 para 8.492 unidades entre 1980 e 1983. 
Em termos sintáticos, esse período apresentou redução na integração global tanto da cidade como do Contorno Rodoviário. No entanto, a redução maior foi para João Pessoa, em função da distensão da malha urbana, que também ocasionou aumento da integração da região lindeira da rodovia. Apesar da redução dos valores, o Contorno Rodoviário ainda apresentou integração global superior à média da cidade (Figura 8).

\section{Figura 7 - Integração global de João Pessoa em 1979}

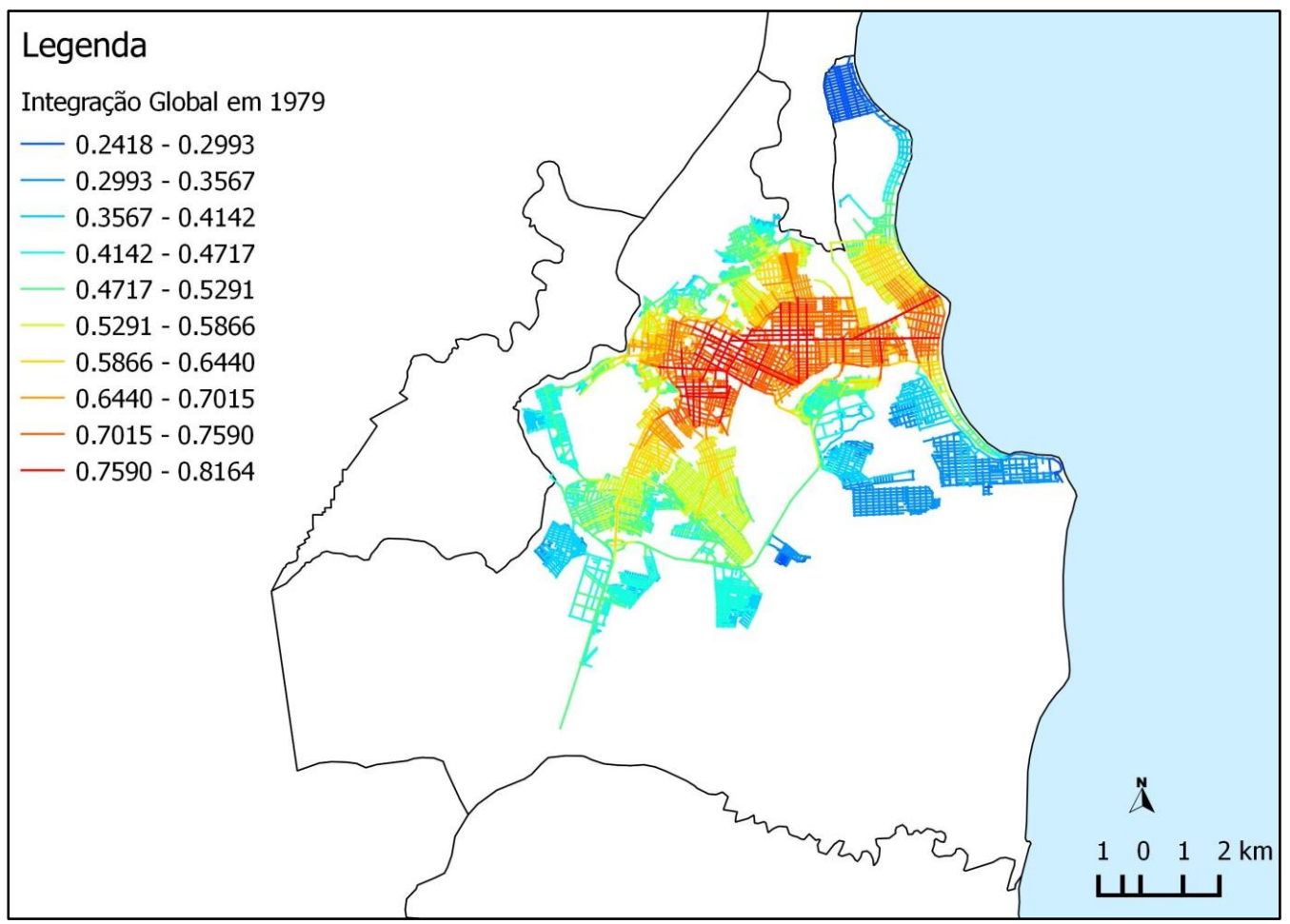

Figura 8 - Integração global de João Pessoa em 1985

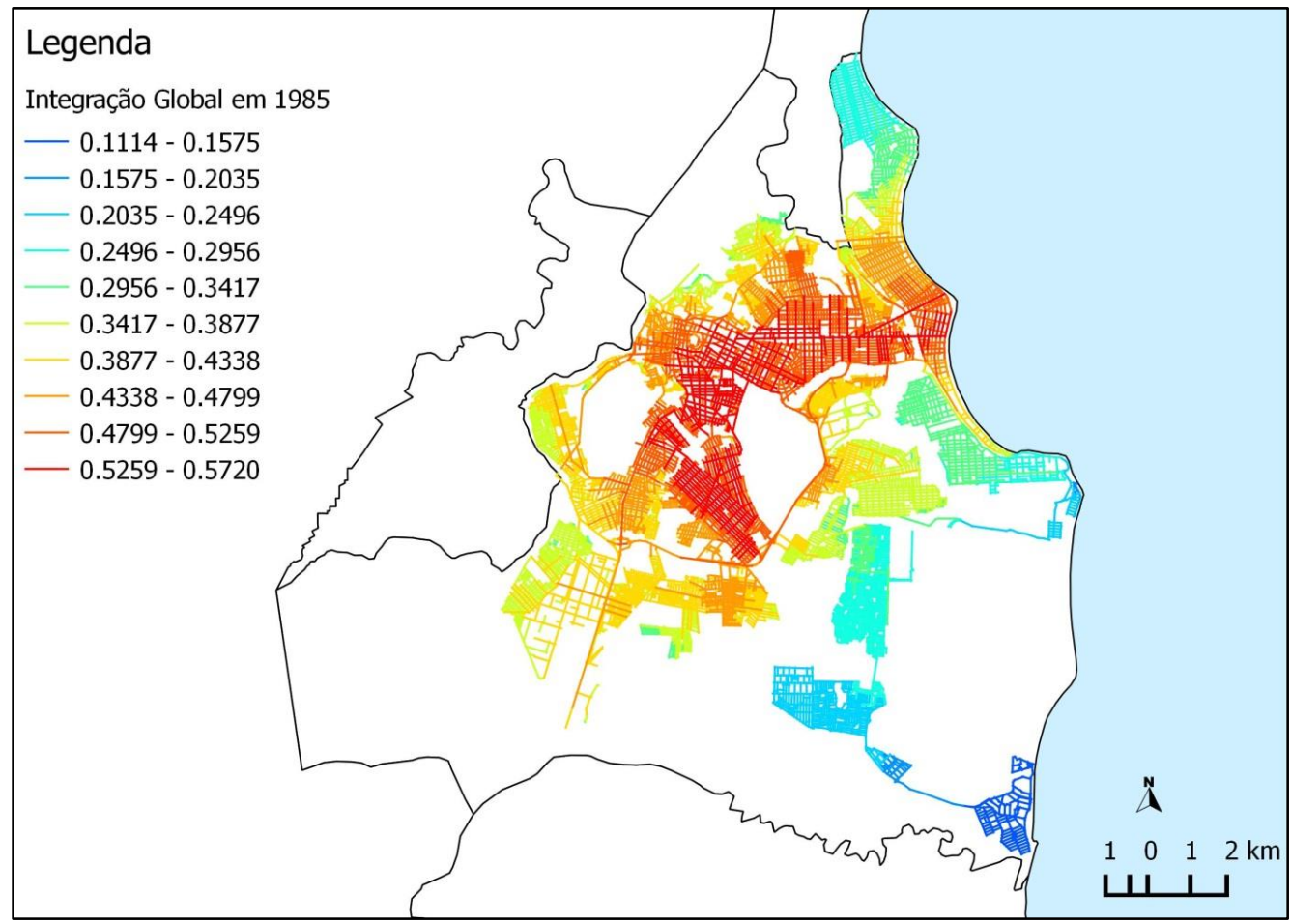

186 Castro, A. A. B. de C.; Melo, R. A. de; Silveira, J. A. R. da; Silva, G. J. A.; Lapa, T. A. 
Entre 1985 e 1994 houve um processo de verticalização e de apropriação dos vazios produzidos pelo espraiamento da cidade. Com o fim da atuação do BNH, em 1986, a produção de conjuntos habitacionais se reduziu. Até o início da década de 1990 o restante da área de influência direta da BR-230 foi ocupado. Na porção sudeste da cidade observou-se o crescimento e adensamento do Conjunto Paratibe, em fase de crescimento, e parte da Costa do Sol, em processo de ocupação. Ainda nesse mesmo contexto e, na parte sudoeste da cidade, encontram-se loteamentos que se estruturam próximo ao Distrito Industrial, e ao sul da cidade o adensamento do Conjunto Valentina de Figueiredo e de loteamentos que se encontram em expansão e que se originaram a partir desse último (SOUZA; SILVA, 2011).

Os valores sintáticos globais, em 1994, obtiveram aumento em relação a 1985, tanto na média da cidade como no Contorno Rodoviário; assim a integração global da rodovia ainda permanece superior à média de João Pessoa. O preenchimento de vazios, de áreas contíguas à faixa de domínio da BR-230, bem como a desaceleração do processo de espraiamento da área urbana contribuíram para a estabilidade dos valores (Figura 9).

Da segunda metade da década de 1990 até 2004, em função da incapacidade do poder público em conter o crescimento desordenado e da especulação imobiliária, acontece o que se pode chamar de "ponto de chegada" do estágio de crescimento, com o retorno do processo de adensamento e a conclusão da ocupação da área de influência direta da BR-230. Com um território expansível relativamente reduzido, começam a ocorrer interfaces diferentes, características do terceiro estágio das transformações urbanas, ditas de combinações e conflitos.

Os valores sintáticos, tanto da cidade de João Pessoa quanto da BR-230, obtiveram pouca variação, cujos valores permaneceram estáveis entre 1994 e 2004. A integração global reduziu-se em pequena escala, mas manteve os valores da rodovia superiores à média da cidade (Figura 10). Esse fato pode estar associado com a desaceleração da distensão da malha urbana, uma vez que o padrão de adensamento desse período foi ocupar os vazios urbanos decorrentes da distensão ocorrida anteriormente (Tabela 3).

Figura 9 - Integração global de João Pessoa em 1994

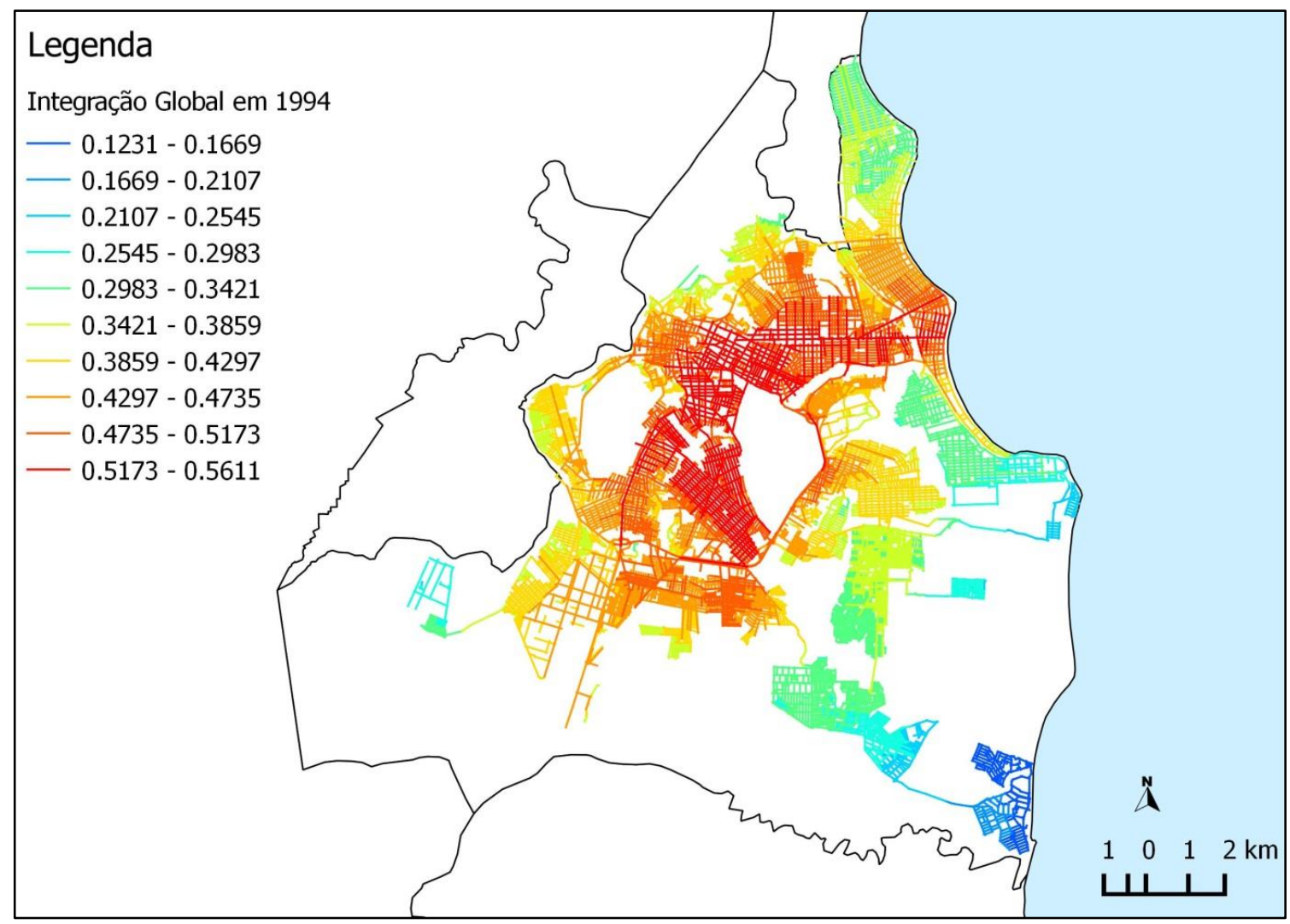


Figura 10 - Integração global de João Pessoa em 2004

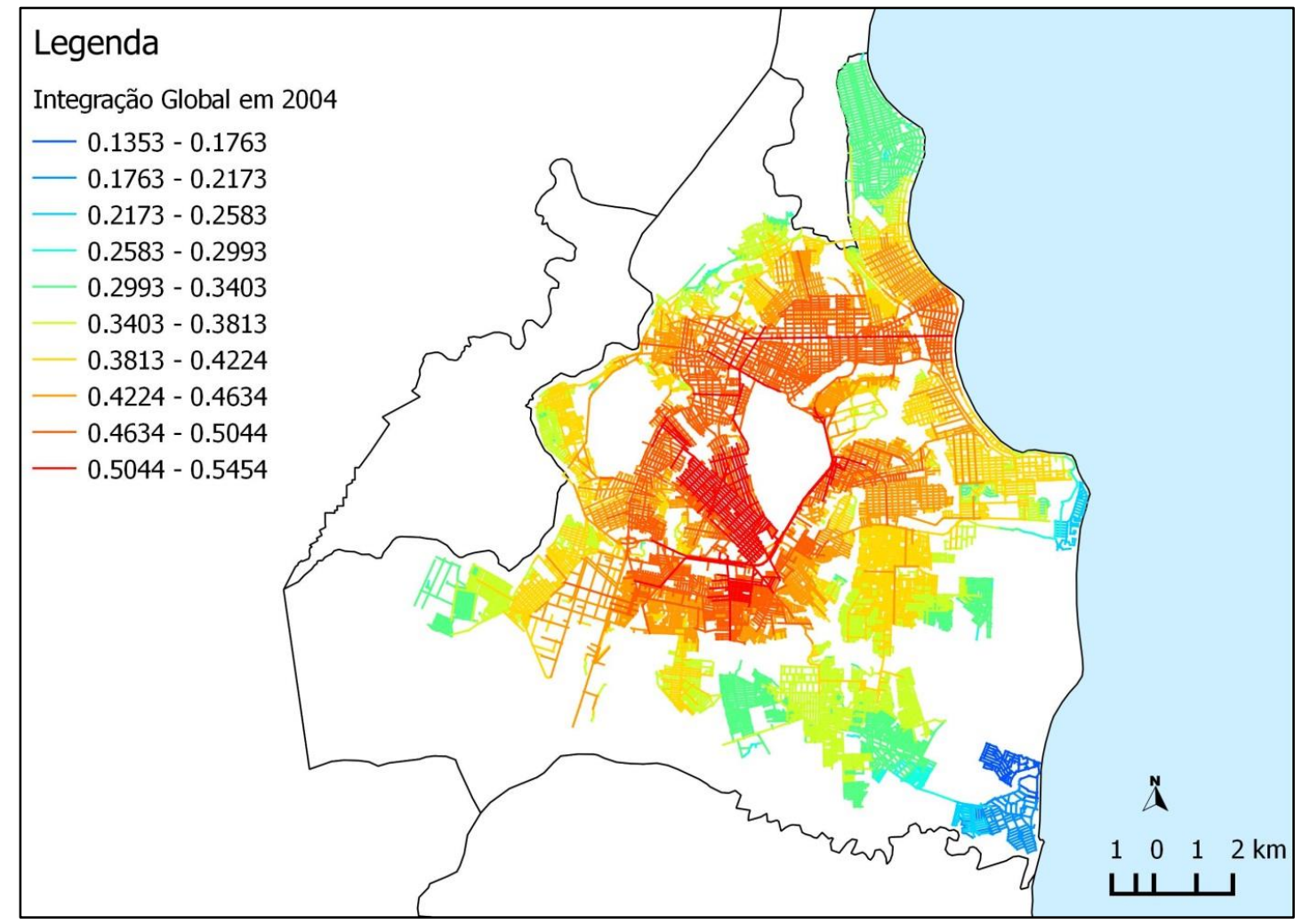

Tabela 3 - Integração global durante o estágio de crescimento (1970-2004)

\begin{tabular}{ccc}
\hline Ano & João Pessoa & Contorno Rodoviário \\
\hline 1979 & 0,513 & 0,5653 \\
1985 & 0,3905 & 0,4926 \\
1992 & 0,4001 & 0,5119 \\
2004 & 0,3966 & 0,51 \\
\hline
\end{tabular}

A partir dos dados obtidos é perceptível a queda na integração morfológica da cidade e da rodovia, principalmente a partir da década de 1980, quando ocorreu a maior distensão do tecido urbano de João Pessoa. Nesse mesmo período a rodovia também passou a ocupar uma posição central na cidade, o que fez aumentar sua integração com esta. Dessa forma, a BR-230 passa a ter importância nos deslocamentos intraurbanos e também passa a exercer a função de carrear fluxos e deslocamentos locais cotidianos. No entanto, ao final do estágio de crescimento, a rodovia se consolidou como um dos espaços mais integrados da cidade (Tabela 3 ).

Em 2004 a malha urbana de João Pessoa alcançou a extensão de $107,3 \mathrm{~km}^{2}$, um aumento de 19,75 $\mathrm{km}^{2}$, o equivalente a $22,57 \%$ em relação a 1994 , e $75,98 \mathrm{~km}^{2}$ em relação a 1970, o equivalente a $342,59 \%$. Espacialmente, é visível que a distensão urbana ocorrida entre 1970 e 2004 concentrou-se na porção sul da cidade, em áreas estruturadas pela BR-230. A rodovia e a cidade seguiram tendências de crescimento aproximadas, com taxas de 40,76\% de crescimento médio de João Pessoa e de 40,37\% de crescimento médio ao longo da rodovia, o que demonstra a importância da rodovia no processo de ocupação territorial (Figuras 11 e 12).

\section{Estágio de combinações e conflitos}

O período entre 2004 e 2013 ficou caracterizado como o terceiro estágio da lógica evolutiva do tecido urbano proposto por Panerai et al. (1986, 2004, 2013), que expôs as interfaces biunívocas entre a cidade e o Contorno Rodoviário em termos de modificações no uso da terra urbana, acessibilidade, segregação socioespacial e processos de favelização. A estagnação do crescimento ao longo da BR-230 marca a transição do estágio de crescimento para a de combinações e conflitos, de modo não linear, cujas interfaces, em processo de consolidação, foram moldadas nos anos anteriores. É importante anotar aqui 
sobreposições e interseções de elementos e processos ao longo dos três estágios dessa metodologia.

Esse cenário resultou em um crescimento territorial de proporções menores ao registrado nos anos anteriores. Em 2013 a cidade de João Pessoa tinha $118,17 \mathrm{~km}^{2}$ de área urbana, com crescimento de $10,82 \%$ em relação a 2004. Além de ser a menor taxa de crescimento urbano registrada desde 1963, não houve distensão considerável no tecido urbano. A área de influência direta do contorno rodoviário não sofreu adensamento em virtude de o processo de urbanização ao longo da rodovia já ter ocupado todas as terras possíveis em 2004 (Figura 13).

Figura 11 - Taxa de crescimento de João Pessoa e do Contorno Rodoviário entre 1970 e 2004

Taxa de Crescimento do Tecido Urbano (\%)

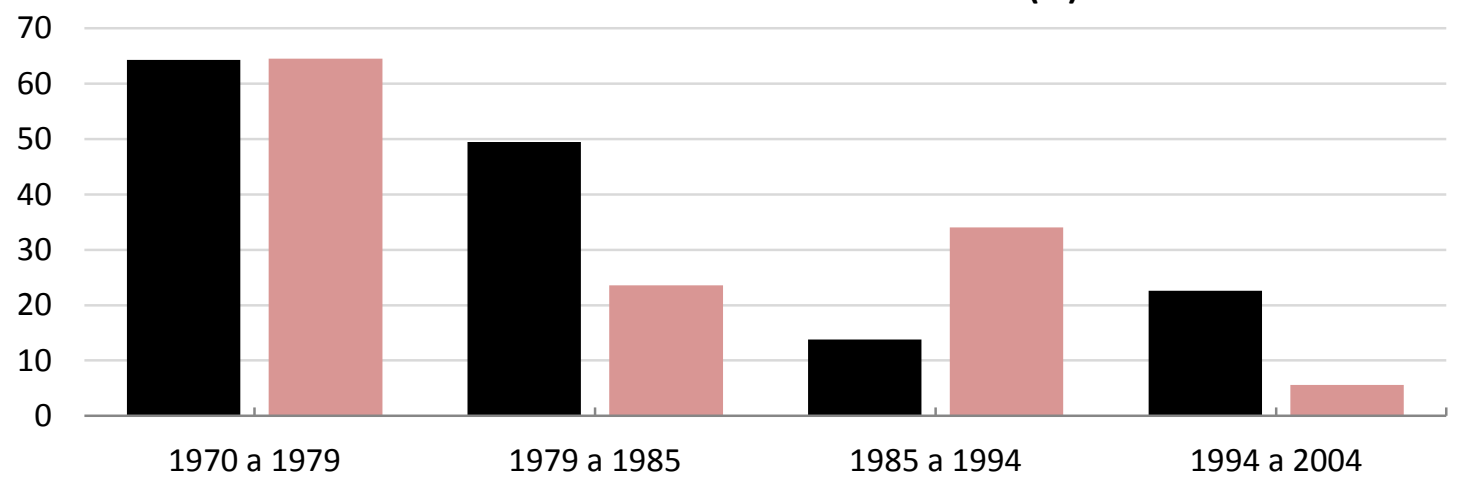

— Crescimento de João Pessoa (\%) C Crescimento ao Longo do Contorno Rodoviário(\%)

Figura 12 - Crescimento urbano de João Pessoa entre 1970 e 2004

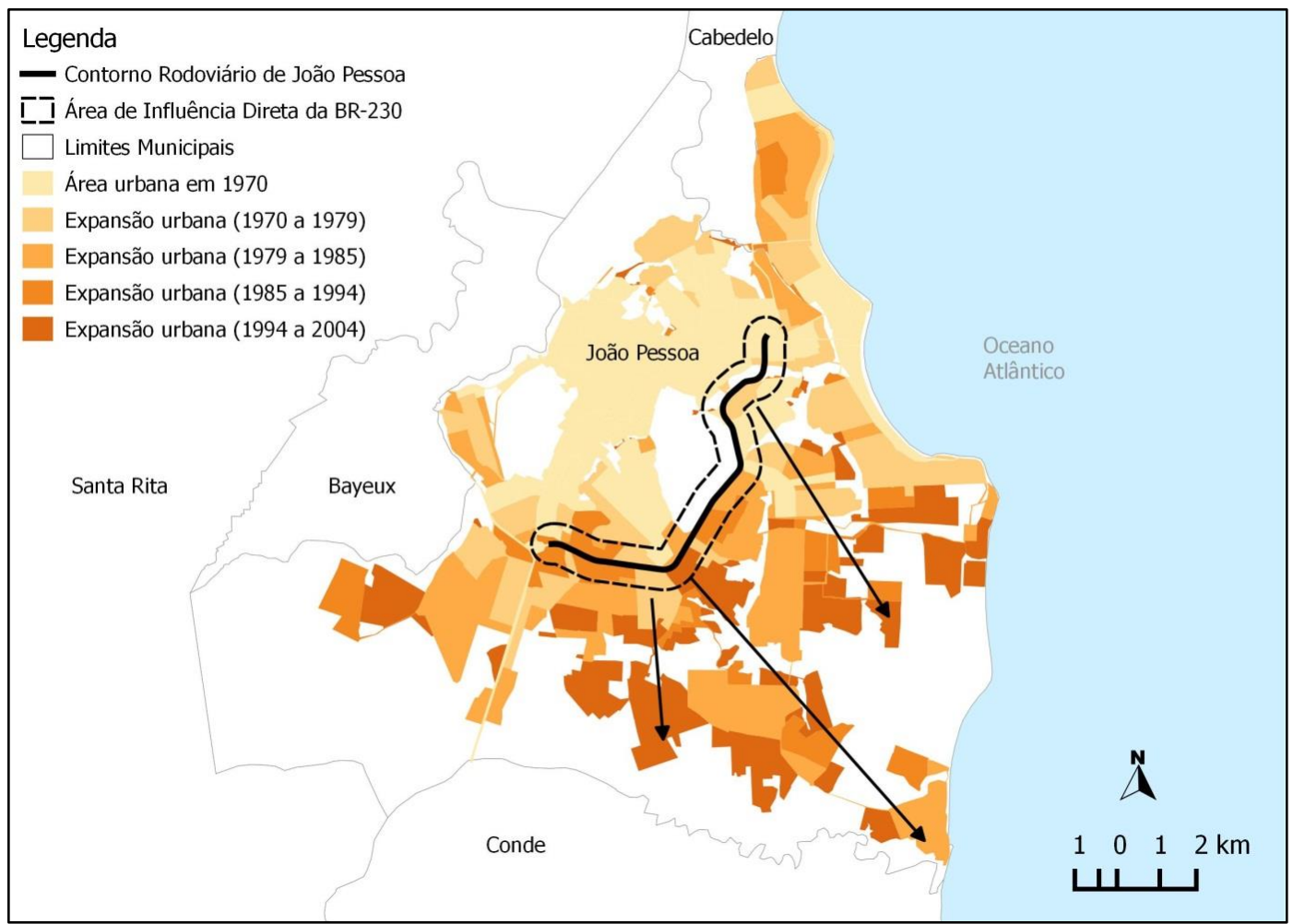


Figura 13 - Crescimento urbano de João Pessoa entre 2004 e 2013

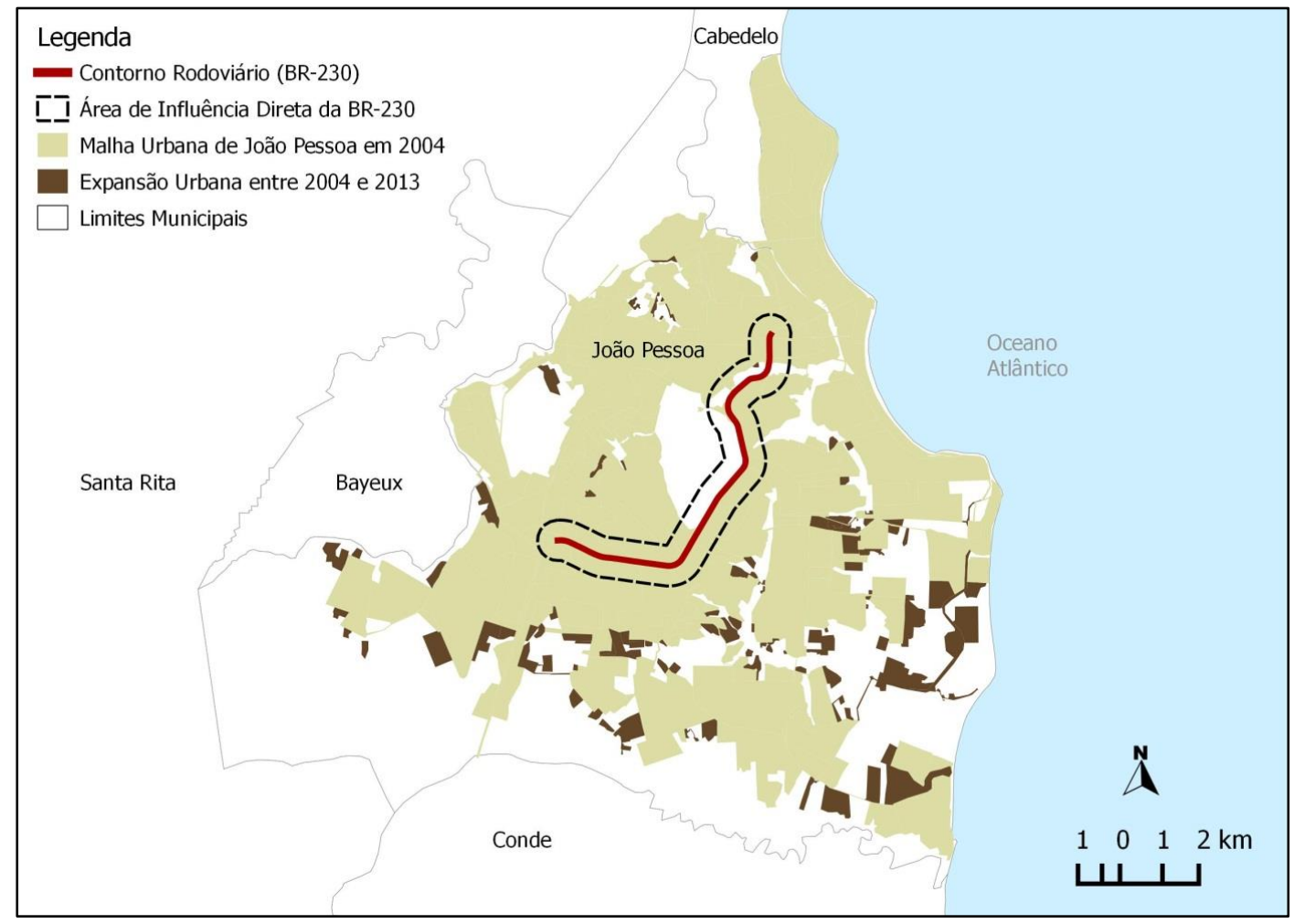

Os valores sintáticos de João Pessoa e da BR-230 sofreram alterações mais significativas que nos períodos anteriores. Com a desaceleração do espraiamento da cidade e a ocupação de vazios produzidos pelo adensamento urbano em direção ao sul, a integração global média da cidade e do Contorno Rodoviário sofreram aumento. O aumento da conectividade em detrimento do aumento da extensão territorial contribuiu para esse cenário. Assim, o Contorno Rodoviário de João Pessoa, nos dias atuais, está localizado na porção mais integrada globalmente da cidade, cujo principal reflexo é sua importância para a acessibilidade macroespacial da cidade (Tabela 4).

Espacialmente, é visível a inserção do eixo rodoviário da BR-230 no setor mais integrado globalmente da malha urbana como uma das principais rotas acessíveis da cidade, do ponto de vista da conformação morfológica do sistema viário. Enquanto a BR-230 se conforma como ponto de acessibilidade macroespacial, localmente a via atua como barreira para a acessibilidade microespacial, por apresentar espaços segregados, tanto contíguos à rodovia em si como ao longo de sua área de influência direta (Figura 14).

Ao analisar os dados históricos de sintaxe espacial ao longo do tempo, é possível afirmar que a rodovia se consolidou no percurso histórico de evolução urbana como um dos espaços mais integrados globalmente de João Pessoa. Após a implantação da rodovia, por sua vez, verificou-se a redução da integração global da cidade, como também ao longo do tempo e do espraiamento da urbe.

No final da década de 1970 a rodovia já apresentava valores maiores que a média da cidade, esta que obteve o menor valor médio em 1985, fato que confirma essa época como o período de maior distensão da malha urbana da cidade. Apesar das variações posteriores nos valores, o Contorno Rodoviário se manteve mais integrado do que a cidade como um todo até os dias atuais. Assim, pode-se observar igualmente a influência da BR-230 no processo de transformação dos espaços mais segregados da cidade (Figura 15).

A ocupação edilícia ao longo da rodovia mostra um padrão diferente do encontrado nos corredores urbanos radiais principais. Apesar de estar completamente urbanizada, a área de influência direta da rodovia encontra-se fragmentada em relação à área edificada em função do uso do solo, da faixa de domínio, do zoneamento e das barreiras físicas, a exemplo da mata do Buraquinho e do vale do Rio Jaguaribe. Assim, a área de influência direta da BR-230 possui $2,93 \mathrm{~km}^{2}$ de área edificada, menos de um terço da área total. A Avenida Epitácio Pessoa, a título de comparação, 
possui mais da metade de sua área de influência direta ocupada por edificações (Figura 16).

Ainda em relação ao uso da terra urbana, outra consequência da implantação do Contorno Rodoviário foi o surgimento de favelas. Ao longo do eixo da BR-230 foi identificada $0,449 \mathrm{~km}^{2}$ de áreas ocupadas por comunidades subnormais. Esse valor, com referência à área construída ao longo da BR-230, equivale a $15,32 \%$. O valor dentro do raio do eixo da BR-230 é maior que a média da cidade, de $3,67 \%$ (Figura 17).

Tabela 4 - Variação da integração global entre 2004 e 2013

\begin{tabular}{ccc}
\hline Local & Integração em 2004 & Integração em 2013 \\
\hline João Pessoa & 0,3966 & 0,4195 \\
Contorno Rodoviário & 0,5100 & 0,5207 \\
\hline
\end{tabular}

Figura 14 - Integração global de João Pessoa em 2013

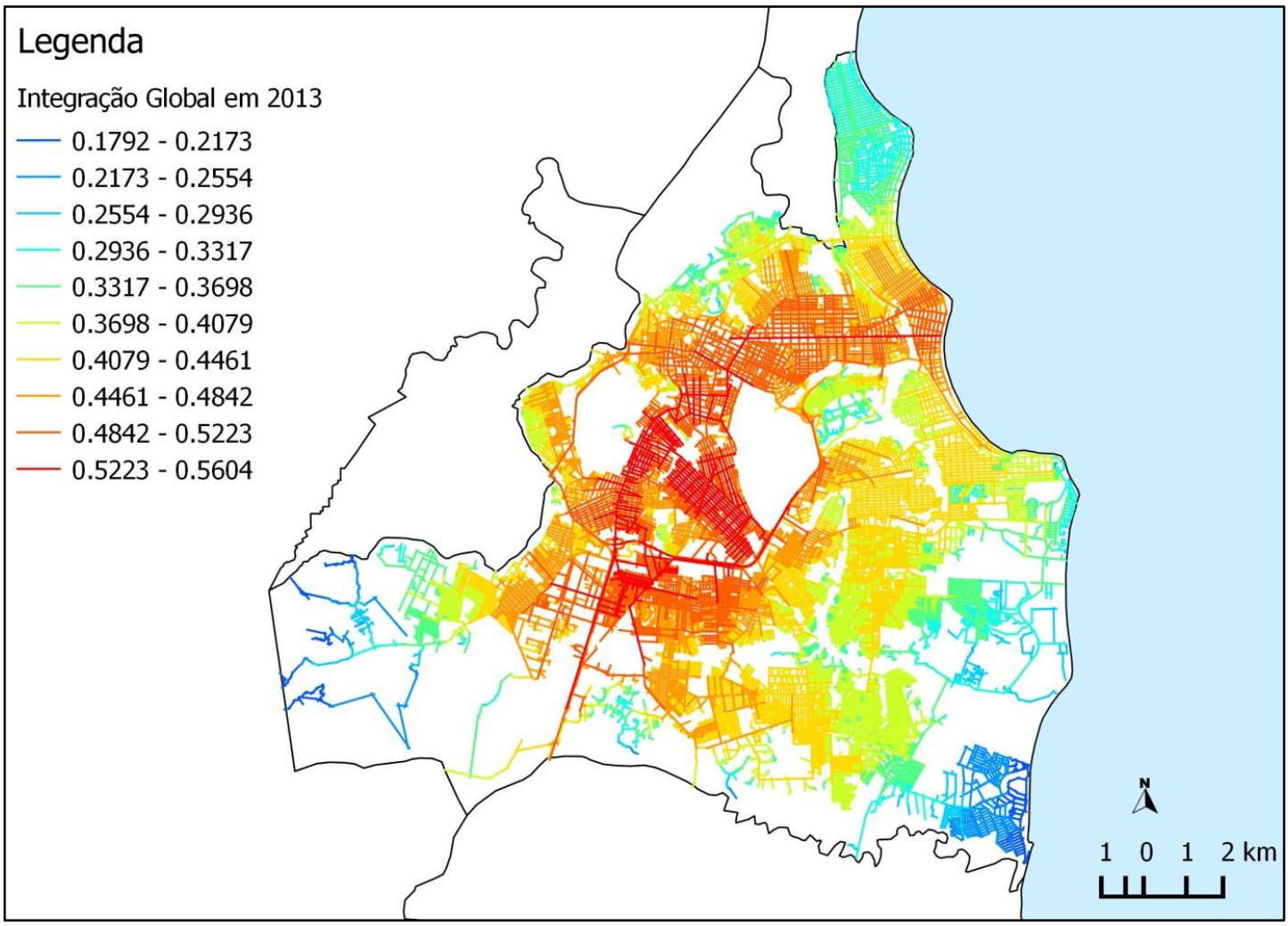

Figura 15 - Evolução da integração global entre 1963 e 2013

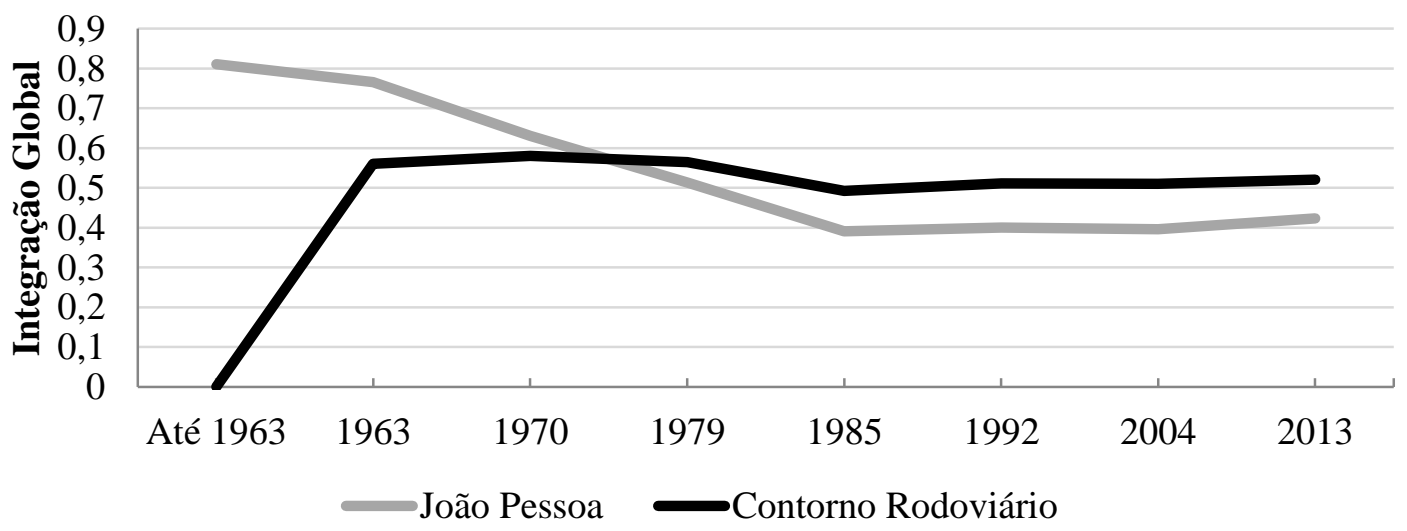


Figura 16 - Área edificada ao longo do Contorno Rodoviário

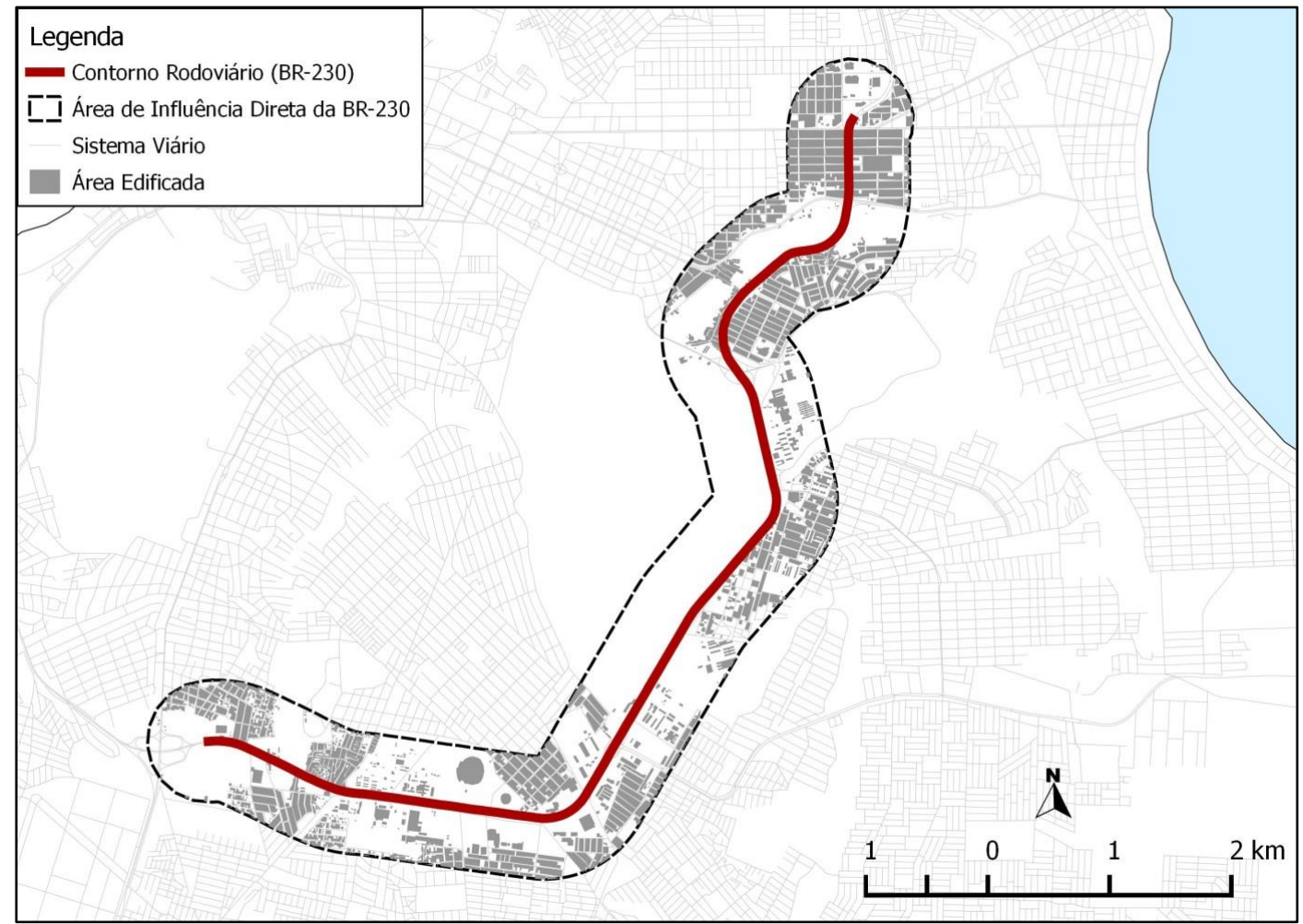

Figura 17 - Mapa de favelas ao longo do Contorno Rodoviário

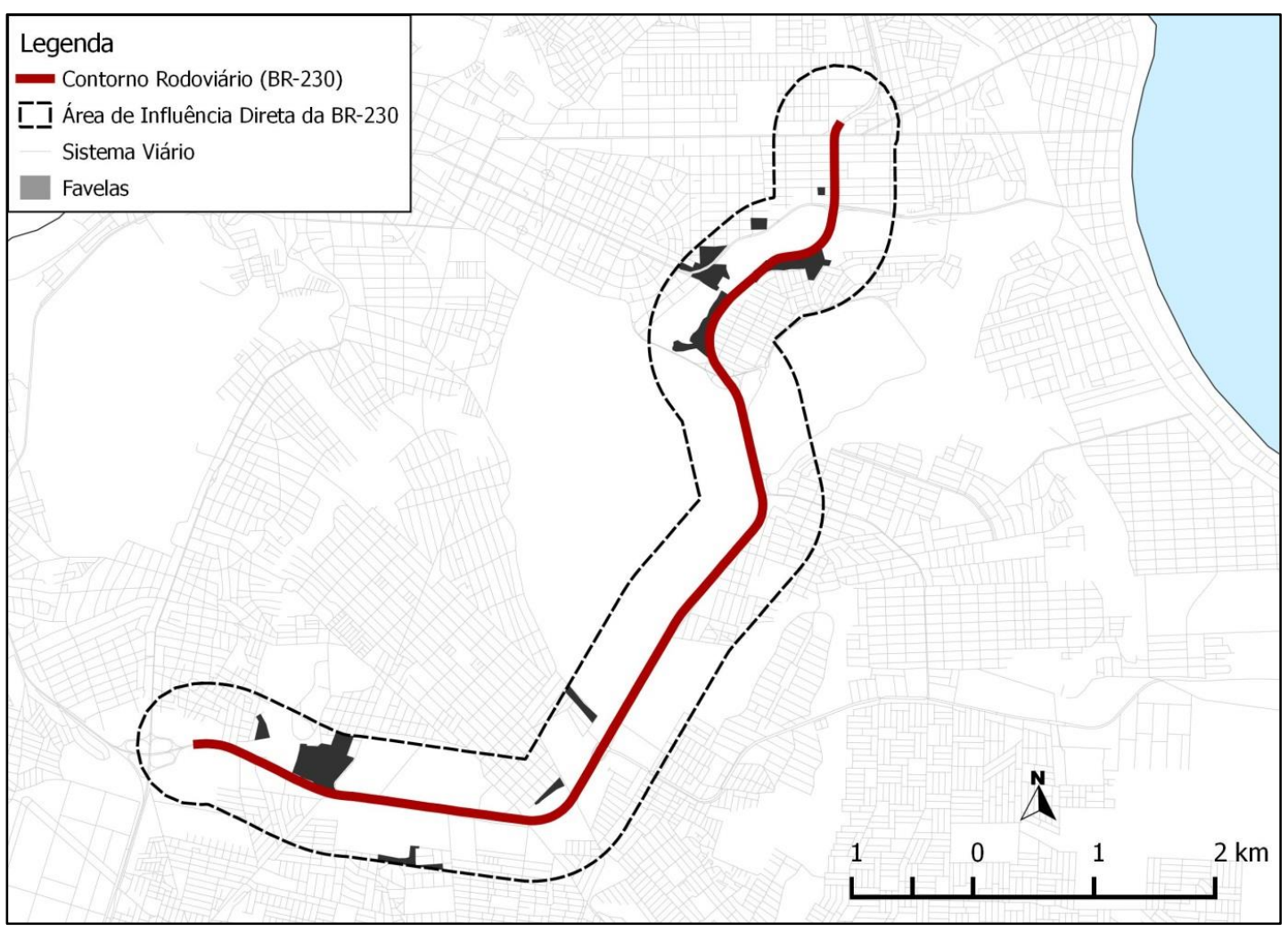

192 Castro, A. A. B. de C.; Melo, R. A. de; Silveira, J. A. R. da; Silva, G. J. A.; Lapa, T. A. 
As interfaces entre a rodovia e a cidade também trouxeram implicações nos deslocamentos de pedestres. Com o adensamento urbano ao longo do percurso da rodovia, aumentaram também as dinâmicas sociais, que implicam maior quantidade de deslocamentos entre os lados da rodovia.

As dificuldades de deslocamento de pedestres na via têm como uma das principais consequências o número de acidentes envolvendo veículos e pedestres. Entre 2005 e 2011 a Polícia Rodoviária Federal contabilizou 259 atropelamentos na BR230 entre os $\mathrm{Km} 0$ e 28 (trecho Cabedelo-João Pessoa), dos quais 127 ocorreram no Contorno Rodoviário de João Pessoa, cerca de $49 \%$ do total. Esse fato mostra a intensidade dos conflitos de fluxos e deslocamentos ao longo do eixo rodoviário intraurbano (Figura 18).

Os locais com maior concentração de atropelamentos são o $\mathrm{Km} 25$ (nas proximidades do Estádio José Américo de Almeida), com 22 atropelamentos, e o Km 27 (no início do viaduto Ivan Bichara), com 25 atropelamentos, regiões onde há a presença de uso do solo urbano misto (residencial, comercial e institucional). Outros trechos críticos estão localizados em zonas residenciais, a exemplo dos bairros Ernani Sátiro, Ernesto Geisel, Jardim São Paulo e Castelo Branco (Figura 19).

O estágio de combinação e conflitos expôs os resultados das interfaces entre o Contorno Rodoviário da BR-230 e a cidade de João Pessoa após o processo de expansão urbana ao longo da rodovia, com mudanças no uso e ocupação da terra urbana, favelização e alterações na acessibilidade, na escala macro e microespacial. Dessa forma, ao longo do processo evolutivo é perceptível a configuração de cada estágio evolutivo capturado a partir das interfaces entre o Contorno Rodoviário da BR-230 e o espaço intraurbano da cidade de João Pessoa (Figura 20).

A implantação do contorno rodoviário de João Pessoa levou à urbanização de áreas além dos limites do vale do Rio Jaguaribe, cuja conformação geográfica representava um entrave para a apropriação de espaços mais avançados ao sul da cidade. Além da urbanização da região, onde atualmente se encontra o bairro dos Bancários, o Contorno Rodoviário atraiu a implantação do conjunto Cristo Redentor. Os dois fatos demonstram a atração exercida pela rodovia para o processo de crescimento urbano que a cidade passou nas décadas seguintes.

Entre os anos de 1963 e 1970 o Contorno Rodoviário da BR-230, que então delimitava a área urbana de João Pessoa, foi gradativamente ocupado por equipamentos institucionais $\mathrm{e}$ conjuntos habitacionais voltados para a população de baixa renda. A rodovia foi um dos alicerces para o crescimento da cidade em direção ao sul, segundo os achados desta pesquisa, confirmando, nesse caso, as interfaces rodoviário-urbanas. Esse fato marcou o primeiro estágio da lógica evolutiva de Panerai, ou seja, o estágio de superação de limites geográficos.

O estágio de crescimento expôs o padrão fragmentado, horizontal e disperso do processo de expansão urbana ocorrido entre as décadas de 1970 e 2000. Nos primeiros quinze anos desse estágio ocorreu a maior distensão da malha urbana, cujos novos limites alcançaram o Rio Gramame. A redução de espaços passíveis de urbanização provocou a desaceleração do crescimento na última década, quando comparado ao período anterior.

O terceiro estágio, de combinações e conflitos, mostrou os resultados do processo de expansão urbana, quando o Contorno Rodoviário da BR-230 apresentou-se como uma via integrada na escala macroespacial, com valores sintáticos superiores à média da cidade, dada sua posição central no espaço geográfico da cidade. No entanto, identificou-se sua situação segregada na escala microespacial pela baixa conectividade com as vias lindeiras, bem como pelas dificuldades de travessias urbanas, nas quais foi registrado aumento no número de atropelamentos de pedestres. 
Figura 18 - Atropelamentos na BR-230 por ano

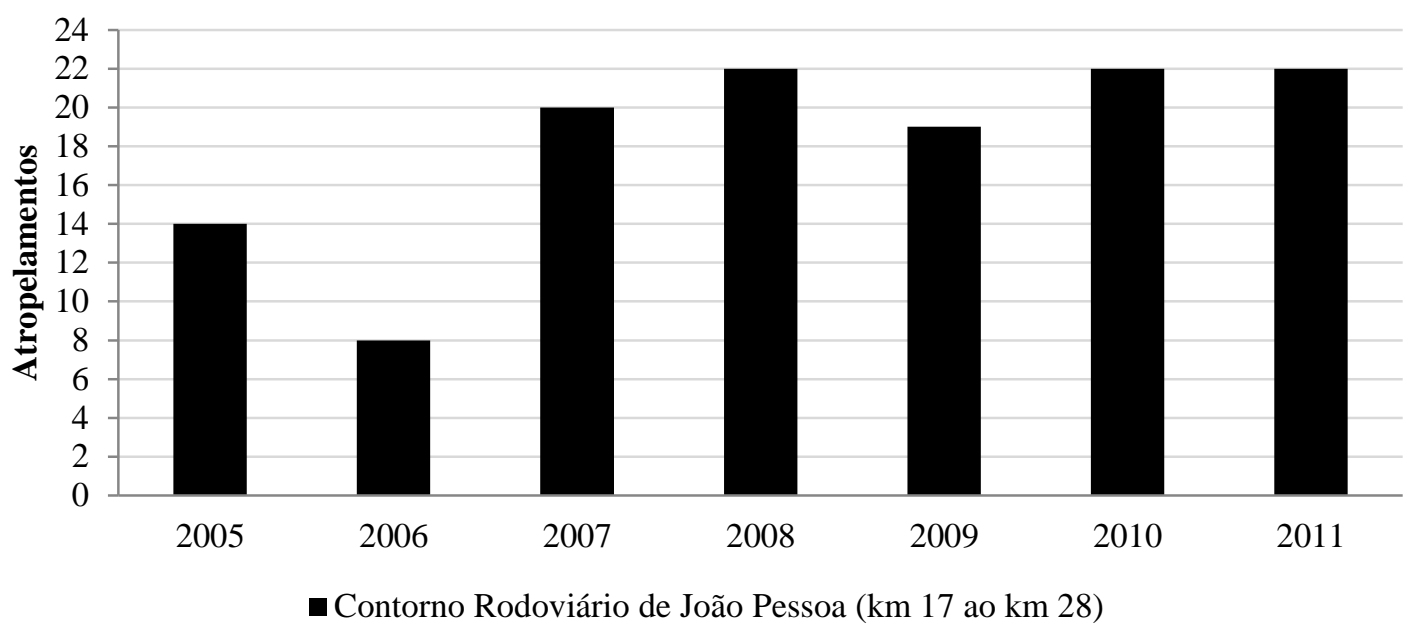

Fonte: dados estatísticos de acidentes de trânsito do Departamento de Polícia Rodoviária Federal (BRASIL, 2005, 2006, 2007, 2008, 2009, 2010, 2011).

Figura 19 - Atropelamentos na BR-230 por Km

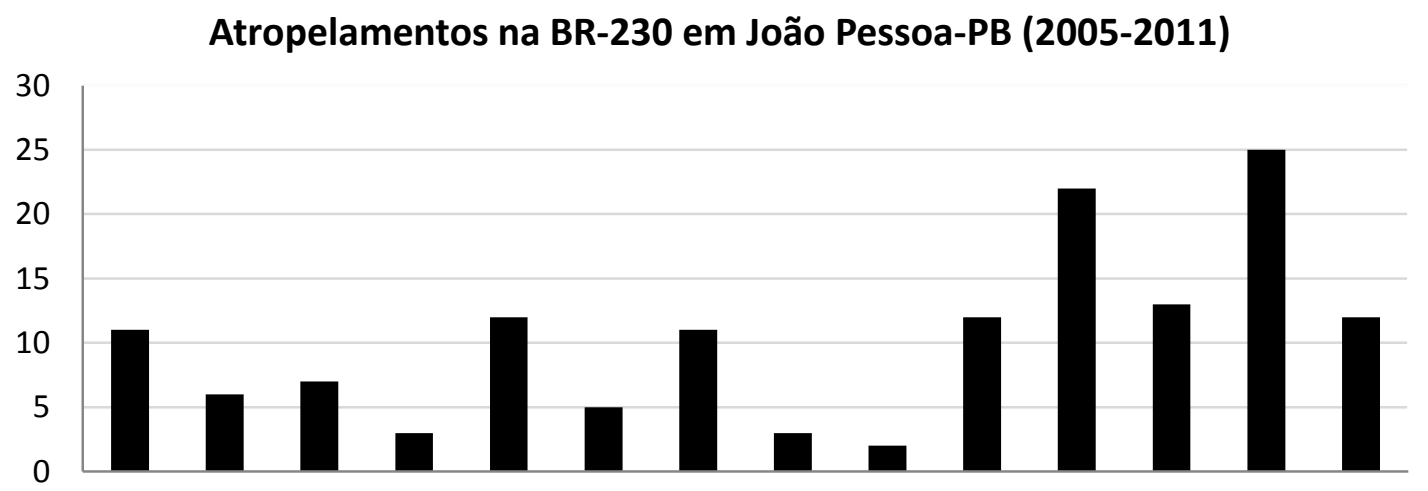

km 15 km 16 km 17 km 18 km 19 km 20 km 21 km 22 km 23 km 24 km 25 km 26 km 27 km 28

Fonte: dados estatísticos de acidentes de trânsito do Departamento de Polícia Rodoviária Federal (BRASIL, 2005, 2006, 2007, 2008, 2009, 2010, 2011). 
Figura 20 - Resumo dos estágios evolutivos de João Pessoa

Estágio de Superação de Limites (1963-1970)

- Implantação da BR-230;

- Ocupação além dos limites do Vale do Jaguaribe;

- Crescimento na direção sudeste;

Crescimento Bruto: $10,94 \mathrm{~km}^{2}$

Crescimento Relativo:53,68\%

- BR-230

Malha Urbana até 1963

Crescimento entre 1963 e 1970

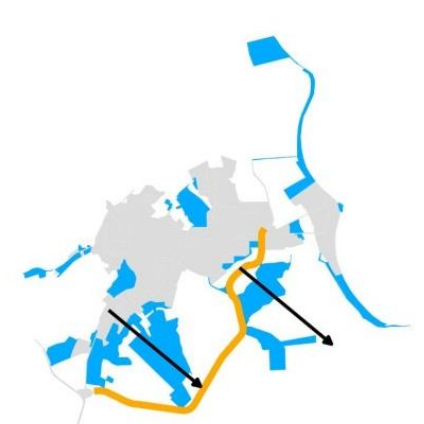

\begin{tabular}{llll}
0 & $2 \quad 4 \mathrm{~km}$ & \\
\hline
\end{tabular}

Estágio de Crescimento (1970-2004)

- Crescimento na direção sul e sudeste;

- Distenção da malha urbana;

- Criação de novas franjas urbanas;

Crescimento Bruto: 75,98 km²

Crescimento Relativo: $242,59 \%$

BR-230

Malha Urbana até 1970

Crescimento entre 1970 e 2004

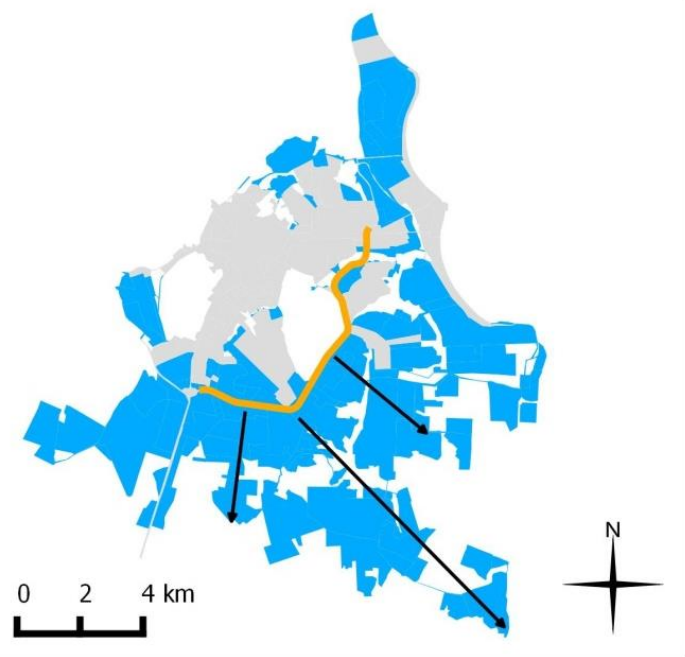

Estágio de Combinação e Conflitos (2004-2013)

- Conflitos e alterações de uso do solo;

- Segregação, favelização;

- Conflitos de Circulação e Acidentes;

Crescimento Bruto: $10,87 \mathrm{~km}^{2}$

Crescimento Relativo: $10,13 \%$

BR-230

Malha Urbana até 2004

Crescimento entre 2004 e 2013

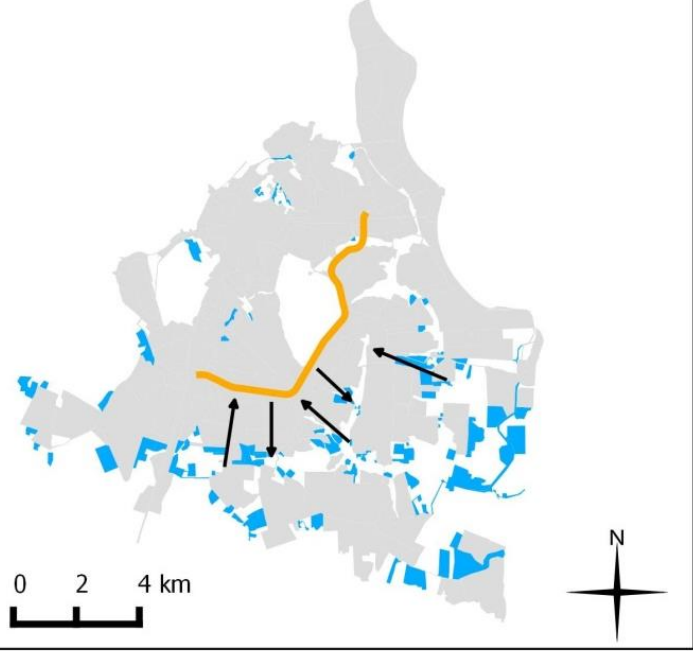


A BR-230, ao se mostrar importante na função de eixo de ligação macroespacial no espaço intraurbano de João Pessoa, também se mostrou, por outro lado, um elemento de segregação socioespacial, ao concentrar em sua região de entorno a classe de baixa renda, bem como ao estabelecer dificuldades de travessia entre os lados da via.

\section{Considerações finais}

As relações entre o estabelecimento de um contorno rodoviário e as implicações no desenvolvimento espacial de áreas urbanas são pouco estudadas, uma vez que a maioria das investigações sobre esses dois aspectos se dá de forma separada. O restrito espaço dedicado ao tema deste artigo e os resultados científicos alcançados nesta pesquisa, tanto em termos metodológico-conceituais quanto empíricos, demonstram o relevo da questão tratada. No campo metodológico específico, o volume de contribuições é limitado e é escasso o número de publicações, embora se verifique qualidade nos estudos realizados. As pesquisas não se inscrevem em um âmbito sistêmico e integrado de procedimentos para o exame rodoviáriourbanístico. Assim, o corpo teórico-metodológico e sua aplicação empírica, aqui conduzida, foram elaborados com a finalidade de preencher essas lacunas científicas, tanto de método aplicado quanto de visão ampliada das interfaces biunívocas existentes entre contornos rodoviários e expansão urbana. Além disso, sua aplicação também traz a possibilidade de identificar e mensurar fenômenos em estágios urbanos não lineares, seus graus de transformação advindos de intervenções públicas e privadas, e também de comparar, de forma qualitativa e quantitativa, diferentes situações urbanas para contextos diversos, contribuindo para fundamentar outros estudos para a normalização de padrões urbanísticos.

É importante enfatizar que os fenômenos aqui abordados não se deram em fases com transformações no sentido linear, mas ocorreram de modo que estabeleceram sobreposições, interfaces e interseções de elementos e processos ao longo dos três estágios da metodologia proposta por Panerai. Dessa maneira, este trabalho buscou contribuir para o conhecimento científico dos fenômenos intraurbanos, por meio do entendimento das dinâmicas existentes entre eixos rodoviários e as modificações na configuração espacial das cidades, levando em conta o uso do solo e a morfologia.

\section{Referências}

APPLEYARD, D. Liveable Streets. San Francisco: University of California Press, 1981.

BALAKRISHNAN, S. Highway Urbanization and Land Conflicts: the challenges to decentralization in India. Pacific Affairs, v. 86, n. 4, p. 785-811, 2013.

BAUM-SNOW, N. Did Highways Cause Suburbanization? The Quarterly Journal of Economic, v. 122, n. 2, p. 775-805, 2007.

BRASIL. Departamento Nacional de Infraestrutura de Transportes. Norma DNIT 003/2002 - PAD: Criação e Cadastramento de anel ou contorno rodoviário - Padronização. Rio de Janeiro: Diretoria de Planejamento e Pesquisa. Coordenação Geral de Estudos e Pesquisas Rodoviárias, 2002.

BRASIL. Departamento Nacional de Infraestrutura de Transportes. Manual Para Ordenamento do Uso do Solo nas Faixas de Domínio e Lindeiras das Rodovias Federais. 2. ed. Rio de Janeiro: Diretoria de Planejamento e Pesquisa; Coordenação Geral de Estudos e Pesquisas Rodoviárias, 2005.

BRASIL. Empresa Brasileira de Planejamento de Transportes. Diretrizes Para a Classificação Viária. Brasília, 1980.

BRASIL. Ministério da Viação e Obras Públicas. Demonstração das Despesas por Verbas e Consignações. Diário Oficial da União, Brasília, 20 de dezembro de 1962.

BRASIL. Departamento de Polícia Rodoviária Federal. Acidentes por Quilômetro (Resumido). Brasília: 2005.

BRASIL. Acidentes por Quilômetro

(Resumido). Brasília: 2006.

BRASIL. Acidentes por Quilômetro (Resumido). Brasília: 2007.

BRASIL. Acidentes por Quilômetro

(Resumido). Brasília: 2008.

BRASIL. Acidentes por Quilômetro (Resumido). Brasília: 2009.

BRASIL. Acidentes por Quilômetro (Resumido). Brasília: 2010.

BRASIL. Acidentes por Quilômetro (Resumido). Brasília: 2011. 
BREUNIG, F. M.; MELLO, L. F. Evolução da Mancha Urbana ao Longo da Rodovia dos Tamoios (São José dos Campos Caraguatatuba) no período de 2000-2008: uma primeira abordagem. In: ENCONTRO NACIONAL DE ESTUDOS POPULACIONAIS, 17, Caxambú, 2010. Anais... Caxambu: ABEP, 2010.

CAVALCANTE, A. P. H.; JALES, A. W. L. Utilização da Sintaxe Espacial na Análise da Expansão Urbana da Cidade de Fortaleza-CE: uma abordagem morfológica. In: CONGRESSO LUSO BRASILEIRO PARA O PLANEJAMENTO URBANO REGIONAL INTEGRADO E SUSTENTÁVEL, 3., Santos, 2008. Anais... Santos : SIT/CETEPE/EESC/USP, 2008.

CLARK, J. M.; HUTTON, B. J. The Appraisal of Community Severance. Contractor Report 135. Berkshire: Transport and Road Research Laboratory, Department of Transport, 1991.

COUTINHO, M. A. F. Evolução Urbana e Qualidade de Vida: o caso da Avenida Epitácio Pessoa - João Pessoa - PB. 2004. 220 f. Dissertação (Mestrado em Engenharia Civil) Programa Regional de Pós-Graduação em Desenvolvimento e Meio Ambiente, Universidade Federal da Paraíba, João Pessoa, 2004.

DEL RIO, V. Introdução ao desenho urbano no processo de planejamento. São Paulo: Pini, 1990.

DONATO, A. V. M. Expansão Urbana e Periferização em Santarém-PA: estudo sobre o vetor da rodovia Cuiabá-Santarém (BR-163). In: ENCONTRO NACIONAL DOS GEÓGRAFOS , 17., Porto Alegre, 2010. Anais... Porto Alegre: AGB, 2010.

DRON, D.; DE LARA, M. C. Pour une politique soutenable des transports. Paris: La Documentation Française, 1995. Collection des rapports officieles.

FALCÃO, L. S.; CASTRO, A. A. B. C.; SILVEIRA, J. A. R. Produção do Espaço Urbano e Segregação: o caso da Av. Liberdade no município de Bayeux-PB. In: SIMPÓSIO DE ESTUDOS URBANOS, 2., Campo Mourão, 2013. Anais... Campo Mourão: FECILCAM, 2013.

FARRET, R. L. Impacto das Ações Sobre os Transportes no Meio Urbano. Brasília: Editora UnB, 1988.

GREEN, D. L.; WEGENER, M. Sustainable Transport. Journal of Transport Geography, v. 5, n. 3, p. 177-190, 1997.

HILLIER, B.; HANSON, J. The Social Logic of Space. London: Cambridge University Press, 1984.
HILLIER, B. Spatial Sustainability in Cities: organic patterns and sustainable forms. In: INTERNATIONAL SPACE SYNTAX SYMPOSIUM, 7., Stockholm, 2009. Proceedings... Stockholm, 2009.

INSTITUTE FOR TRANSPORTATION AND DEVELOPMENT POLICY; EMBARQ. Life and Death of Urban Highways. March 2013.

Disponível em: <http://www.embarq.org/en/lifeand-death-urban-highways >. Acesso em: 17 mar. 2014.

JIANG, Y.; PENG, Q. The Relationship Between Highways and Urban Roads in Urbanization. CICTP, 2012.

JIANG, F. et al. Measuring Urban Sprawl in Beijing With Geo-Spatial Indices. Journal of Geographical Sciences, n. 17, n. 4, p. 469-478, 2007.

LAVIERI, J. R.; LAVIERI, M. B. Evolução da Estrutura Urbana de João Pessoa (1960 - 1986). João Pessoa: UFPB, 1992.

LIMA, P.; RÊGO, S. Estudo da Urbanização na Zona Sul da cidade de João Pessoa-PB Através de Sensoriamento Remoto e Análise Espacial. In: SIMPÓSIO DE ESTUDOS URBANOS, 1, Campo Mourão, 2011. Anais... Campo Mourão:

FECILCAM, 2011.

MEDEIROS, V. A. S. Urbis Brasiliae ou Sobre as Cidades do Brasil: inserindo assentamentos urbanos do país em investigações configuracionais comparativas. Brasília, 2006. 520 f. Tese (Doutorado em Engenharia Civil) - Faculdade de Arquitetura e Urbanismo, Universidade de Brasília, Brasília, 2006.

MEDEIROS, V. A. S. BARROS, A. P. B.; OLIVEIRA, V. M. A. Cartografia Histórica e Mapas Axiais: uma estratégia para a leitura da expansão urbana. In: SIMPÓSIO BRASILEIRO DE CARTOGRAFIA HISTÓRICA, 4., Porto, 2011. Anais... Porto: UPorto, 2011.

MOUETTE, D. Os Pedestres e o Efeito Barreira. São Paulo, 1998. 257 f. Tese (Doutorado em Engenharia Civil) - Escola Politécnica, Universidade de São Paulo, São Paulo, 1998.

NEGRÃO, A. G. Processo de Produção e Reprodução da Cidade: um estudo sobre os estágios evolutivos ao longo dos espaços estruturados pelo corredor da Avenida Pedro II, João Pessoa, Paraíba. João Pessoa, 2012. 135 f. Dissertação (Mestrado em Engenharia Civil) Programa de Pós Graduação em Engenharia Urbana e Ambiental, Universidade Federal da Paraíba, João Pessoa, 2012. 
NOGUEIRA, A. D. Análise Sintático-Espacial das Transformações Urbanas de Aracaju (1855-2003). Cadernos PPG-AU/AUFBA, Salvador, v. 4, n. 1, p. 59-76, 2005.

OLIVEIRA, J. L. A. Uma Contribuição aos Estudos Sobre a Relação Transporte e Crescimento Urbano: o caso de João Pessoa. João Pessoa, 2006. 195 f. Dissertação (Mestrado em Engenharia Civil) - Programa de PósGraduação em Engenharia Urbana, Universidade Federal da Paraíba, João Pessoa, 2006.

PANERAI, P. et al. Elements d'Analise Urbaine. Bruxelas: Achive d'Architecture Moderne, 1986.

PANERAI, P. et al. Formas Urbanas: a dissolução da quadra. Porto Alegre: Bookman, 2013.

PANERAI, P. et al. Urban Forms: the death and life of the urban blocks. London: Elsevier, 2004.

PEREIRA, F. T. B. Difusão da Arquitetura Moderna na Cidade de João Pessoa (19561974). São Carlos, 2008. 278 f. Dissertação (Mestrado em Engenharia Civil) - Escola de Engenharia de São Carlos, Universidade de São Paulo, São Carlos, 2008.

PIATKOWSKY, R. The Third Option: removing urban highways. Atlanta: School of City \& Regional Planning, Georgia Institute of Technology, 2011.

PINTO, A. F. C. A Implantação de Contornos Rodoviários e as Transformações da Forma Urbana de Pequenas Cidades: estudo de caso da rodovia RS-377 em São Francisco de Assis e Santiago, RS. Porto Alegre, 2012. 114 f. Dissertação (Mestrado em Engenharia Civil) Programa de Pós Graduação em Planejamento Urbano e Regional, Universidade Federal do Rio Grande do Sul, Porto Alegre, 2012.

POLIDORO, M. Reflexões Sobre a Influência da Rodovia BR-369 na Definição dos Padrões de Expansão Urbana dos Municípios no Estado do Paraná. In: Encontro Nacional da Associação Nacional de Pós-Graduação e Pesquisa em Geografia, Goiânia, 9, 2011. Anais... Goiânia: ANGEPE, 2011.

POLIDORO, M.; BARROS, M. V. F. Considerations About the Urban Expansion of Parana's Municipalities Located in the Stretch of BR-369 Highway. Revista Brasileira de Gestão e Desenvolvimento Regional, v. 8, n. 3, p. 322-341, 2012.
POLIDORO, M. et al. Análise Multitemporal da Evolução da Mancha Urbana no Entorno da BR369 dos Municípios Paranaenses. In: ENCONTRO NACIONAL DOS GEÓGRAFOS, 16., Porto Alegre, 2010. Anais... Porto Alegre: AGB, 2010.

RAFAEL, R. A. et al. Caracterização da Evolução Urbana do Município de João Pessoa/ PB Entre os Anos de 1990 e 2006, Com Base em Imagens Orbitais de Média Resolução. In: SIMPÓSIO BRASILEIRO DE SENSORIAMENTO REMOTO, 14, Natal, 2009. Anais... Natal: INPE, 2009.

RIBEIRO, R. J. C; HOLANDA, F. Application of Geotechnology to Urban Configuration. In: INTERNATIONAL SPACE SYNTAX SYMPOSIUM, 4., London, 2003. Proceedings... London, 2003.

SABOYA, R. Sintaxe Espacial. Urbanidades, 03 jul. 2007. Disponível em:

<http://urbanidades.arq.br/2007/09/sintaxeespacial/>. Acesso em: 30 jul. 2013.

SANTOS, M. A Urbanização Brasileira. 5. ed. São Paulo: EDUSP, 2005.

SAVIOLI, M. L. A Cidade e a Estrada: as transformações urbanas do município de Cotia ao longo da rodovia Raposo Tavares. Pós, São Paulo, v. 22, p. 106-121, 2008.

SILVA JÚNIOR, S. B.; FERREIRA, M. A. G. Rodovias em Áreas Urbanizadas e Seus Impactos na Percepção dos Pedestres. Sociedade \&

Natureza, Uberlândia, v. 20, n. 1, p. 221-237, jun. 2008.

SILVA, A. H. et al. Análise Espacial da Evolução de Manchas Urbanas ao Longo de Rodovias Federais Concedidas Utilizando Sensoriamento Remoto. In: SIMPÓSIO BRASILEIRO DE SENSORIAMENTO REMOTO, 13., Florianópolis, 2007. Anais... Florianópolis: INPE, 2007.

SILVEIRA, J. A. R. Percurso e processo de evolução urbana: o caso da Av. Epitácio Pessoa na cidade de João Pessoa. Recife, 2004. 317 f. Tese (Doutorado em Engenharia Civil) - Programa de Pós-Graduação em Desenvolvimento Urbano, Universidade Federal de Pernambuco, Recife, 2004.

SOUZA, J. F.; SILVA, R. M. Transformações Recentes no Uso e Ocupação do Solo nos Bairros de Água Fria e José Américo, João Pessoa-PB. Cadernos do Logepa, v. 6, n. 1, p. 25-40, 2011.

SOUZA, M. L. ABC do desenvolvimento urbano. 3. ed. Rio de Janeiro: Bertrand Brasil, 2007. 
SUDHIRA, H. S.; RAMACHANDRA, T. V.; JAGADISH, K. S. Urban Sprawl: metrics, dynamics and modelling using GIS. International Journal of Applied Earth Observation and Geoinformation, v. 5, n. 1, p. 29-39, fev. 2004.

TAVARES, A. M. P. C. Centralidades Periféricas: o caso do nó de taveiro. Revista Iberoamericana de Urbanismo, v. 10, 2013.

TRAJANO FILHO, F. S. DVPO: arquitetura moderna, estado e modernização (Paraíba, Década de 1930). São Paulo, 2003. Dissertação (Mestrado em Arquitetura e Urbanismo) - Escola de Engenharia de São Carlos, Universidade de São Paulo, São Paulo, 2003.
VAN NES, A. Road Building and Urban Change: a morphological and configurative explanation of how ring roads change the pattern of distribution of shops in city and town centres. In: International Symposium, 3., Atlanta, 2001. Proceedings... Atlanta: Georgia Institute of Technology, 2001.

VAROUDIS, T. DepthmapX 0.30. 2014.

Disponível em:

<http://archtech.gr/varoudis/depthmapX/>. Acesso em: 03 jul. 2015.

VASCONCELLOS, E. A. Transporte Urbano, Espaço e Qualidade: análise das políticas públicas. São Paulo: Annablume, 2001.

VASCONCELLOS, E. A. Transporte e Meio Ambiente: conceitos e informações para análise de impactos. São Paulo: Annablume, 2008.

VILLAÇA, F. O Espaço Intraurbano no Brasil. 2. ed. São Paulo: Studio Nobel, 2001.

\footnotetext{
Alexandre Augusto Bezerra da Cunha Castro

Centro de Tecnologia, Departamento de Arquitetura | Universidade Federal da Paraíba | Via Expressa Padre Zé, s/n, Cidade Universitária, Campus I | João Pessoa - PB - Brasil | CEP 58051-900 | Tel.:(083) 3216-7601 Ramal 7601 | E-mail: alexbccastro@hotmail.com

Ricardo Almeida de Melo

Centro de Tecnologia, Departamento de Engenharia Civil e Ambiental | Universidade Federal da Paraíba | Tel.: (83) $3216-7036$ |

E-mail: ricardo@ct.ufpb.br

José Augusto Ribeiro da Silveira

Centro de Tecnologia, Departamento de Arquitetura | Universidade Federal da Paraíba | Tel.: (083) 3216-7601 Ramal 7601 |

E-mail: ct.laurbe@gmail.com

Geovany Jessé Alexandre Silva

Centro de Tecnologia, Departamento de Arquitetura | Universidade Federal da Paraíba | Tel.: (083) 3216-7601 |

E-mail: galexarq@gmail.com

Tomás Albuquerque Lapa

Departamento de Arquitetura e Urbanismo, Centro de Artes e Comunicação | Universidade Federal de Pernambuco | Av. Prof. Moraes Rego, 1235, Cidade Universitária | Recife - PE - Brasil | CEP: 50670-901 | Tel.: (081) 2126-8000 | E-mail: thlapa@hotmail.com
}

Revista Ambiente Construído

Associação Nacional de Tecnologia do Ambiente Construído

Av. Osvaldo Aranha, $99-3^{\circ}$ andar, Centro

Porto Alegre - RS - Brasil

CEP $90035-190$

Telefone: +55 (51) 3308-4084

Fax: +55 (51) 3308-4054

www.seer.ufrgs.br/ambienteconstruido

E-mail: ambienteconstruido@ufrgs.br 